E International

\title{
Structural Change and the Freight Transport Labour Market
}

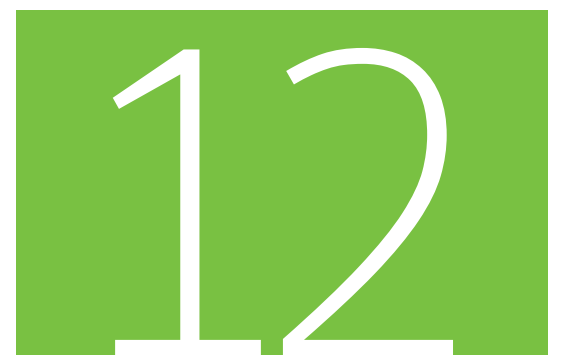

Discussion Paper 2017•12

Mårten Blix

Research Institute of Industrial Economics, Stockholm 


\title{
EInternational Transport Forum
}

\author{
Structural change and \\ the freight transport labour market
}

Discussion Paper No. 2017-12

Prepared for the Roundtable on

Commercial Vehicle On-Board Safety Systems

January 5-6, 2017, Washington, DC

Mårten Blix

Research Institute of Industrial Economics, Stockholm, Sweden

August 2017 


\section{The International Transport Forum}

The International Transport Forum is an intergovernmental organisation with 59 member countries. It acts as a think tank for transport policy and organises the Annual Summit of transport ministers. ITF is the only global body that covers all transport modes. The ITF is politically autonomous and administratively integrated with the OECD.

The ITF works for transport policies that improve peoples' lives. Our mission is to foster a deeper understanding of the role of transport in economic growth, environmental sustainability and social inclusion and to raise the public profile of transport policy.

The ITF organises global dialogue for better transport. We act as a platform for discussion and pre-negotiation of policy issues across all transport modes. We analyse trends, share knowledge and promote exchange among transport decision-makers and civil society. The ITF's Annual Summit is the world's largest gathering of transport ministers and the leading global platform for dialogue on transport policy.

The Members of the Forum are: Albania, Armenia, Argentina, Australia, Austria, Azerbaijan, Belarus, Belgium, Bosnia and Herzegovina, Bulgaria, Canada, Chile, China (People's Republic of), Croatia, Czech Republic, Denmark, Estonia, Finland, France, Former Yugoslav Republic of Macedonia, Georgia, Germany, Greece, Hungary, Iceland, India, Ireland, Israel, Italy, Japan, Kazakhstan, Korea, Latvia, Liechtenstein, Lithuania, Luxembourg, Malta, Mexico, Republic of Moldova, Montenegro, Morocco, the Netherlands, New Zealand, Norway, Poland, Portugal, Romania, Russian Federation, Serbia, Slovak Republic, Slovenia, Spain, Sweden, Switzerland, Turkey, Ukraine, the United Arab Emirates, the United Kingdom and the United States.

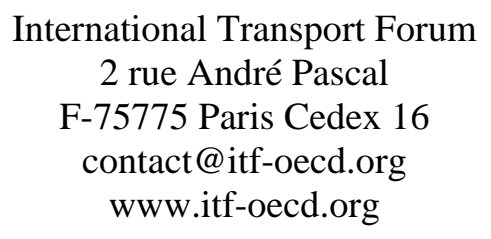

\section{ITF Discussion Papers}

ITF Discussion Papers make economic research, commissioned or carried out in-house at ITF, available to researchers and practitioners. They describe preliminary results or research in progress by the author(s) and are published to stimulate discussion on a broad range of issues on which the ITF works. Any findings, interpretations and conclusions expressed herein are those of the authors and do not necessarily reflect the views of the International Transport Forum or the OECD. Neither the OECD, ITF nor the authors guarantee the accuracy of any data or other information contained in this publication and accept no responsibility whatsoever for any consequence of their use. This document and any map included herein are without prejudice to the status of or sovereignty over any territory, to the delimitation of international frontiers and boundaries and to the name of any territory, city or area. Comments on Discussion Papers are welcome. 


\section{Acknowledgements}

The author would like to thank Charlotta Olofsson for research assistance. For insightful discussions, he would like to thank Therese Rosen Löfstedt at the Volvo Group as well as Christian Levin and Erik Ljungberg at Scania. 


\begin{abstract}
Nations that have managed to become rich have had institutional features that supported incentives for value creation while ensuring that the ways insiders and special interest groups can extract monopoly rents are limited. Improved skills have been a central component of helping individuals and societies to adapt to technological change. As technological progress has led to the disappearance of many difficult and arduous jobs, many new jobs have been created with higher skill content, leading to better productivity and real wage growth. In the long run, the modern economy is set to continue to create new jobs, especially in the service sector. But the required adjustments can lead to poor wage developments and social upheaval in the short-run. This is true for many sectors in the economy and especially so for the freight transport labour market. Technology could lead to strong disruption concentrated to particular groups, such as commercial drivers. Moreover, the effects may come in a more compressed period of time than previous periods of structural change, thus making it tougher for workers to adjust. Two types of policies to reduce the risks are to improve life-long learning and to reduce the risks associated with self-employment. Better education throughout working lives is the key to getting the benefits of technical change. Workers whose skills fall too far behind risk facing dimmer wage and job prospects.

Could regulation aim to slow down the adoption of technical change over and above that motivated by safety concerns, thereby giving the labour market longer time to adapt? Such a policy would be harmful in the medium-to-long run. It would hold back productivity growth, which is the key to increased prosperity. Wage and job polarisation would likely also continue unabated.

JEL Classification: D01, I24, I28, J23, J24.
\end{abstract}




\section{Table of contents}

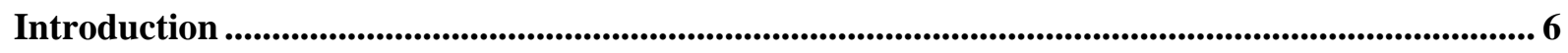

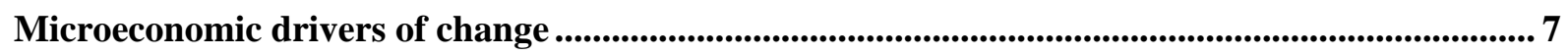

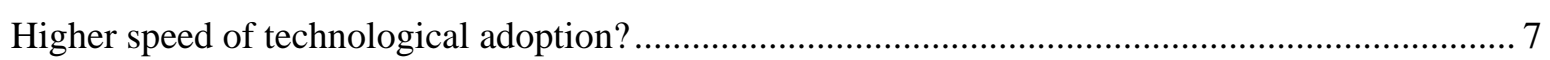

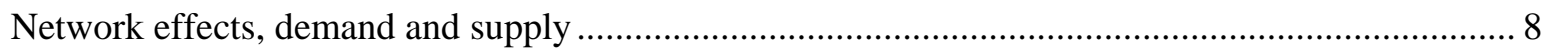

Less capital needed for many digital companies and its implications ............................................. 10

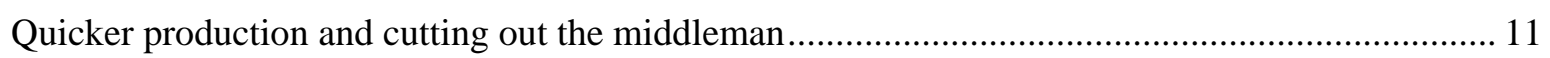

Changes to production: Physical goods becoming digital services.................................................. 12

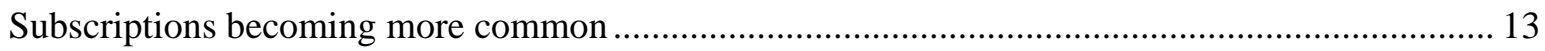

Technology and demography changing the labour market ......................................................... 13

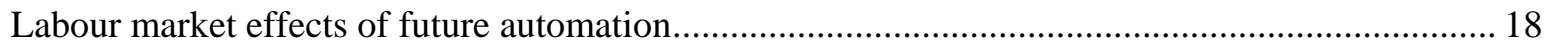

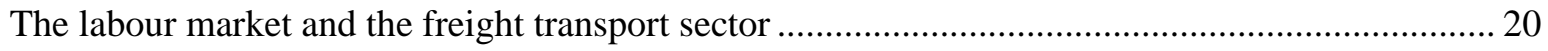

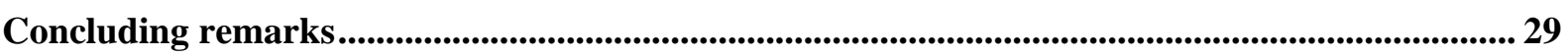

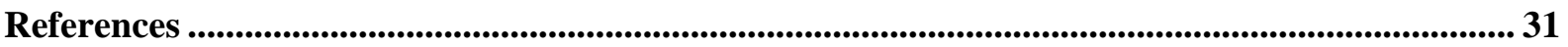

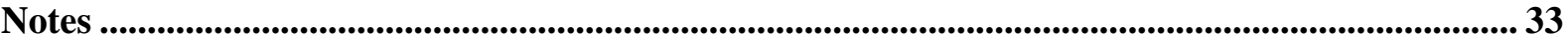

\section{Figures}

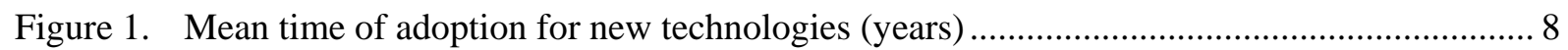

Figure 2. Declining labour share of income in selected industrialised countries................................ 11

Figure 3. Empirical estimates for risk of automation in the whole labour market (percent) .............. 17

Figure 4. Selection of automation risks for the whole labour market and for the

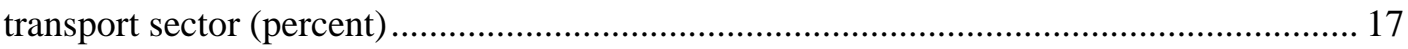

Figure 5. Shifts in employment shares of different types of work (1995-2010)................................ 19

Figure 6. Employees in the transport sector as share of total employment (2014) ............................. 20

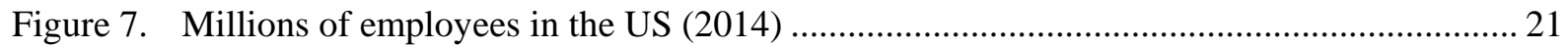

Figure 8. Change in index on employment protection legislation (EPL) (1990-2013) ..................... 26

Figure 9. The young increasingly in temporary jobs: 15-24 years old as share of total dependent

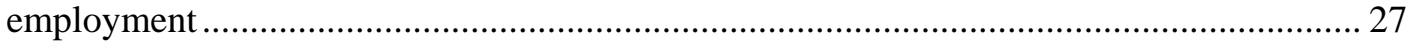

\section{Tables}

Table 1. OECD assessment of statutory difference benefits permanent, temporary and selfemployed. 


\section{Introduction}

From the beginning of the Industrial Revolution, automation has been a key driver of productivity growth in the manufacturing industry. During this time, service sector productivity has also improved but at a more modest pace. With rapid advances in digital technologies, that is about to change and modern economies are standing at the precipice of major upheaval. The changes are affecting virtually all services at the same time, but some areas are more advanced than others. In particular, retail and transportation are likely to be at the forefront of this transformation, driven by a combination of technological improvements, consumer demand and cost-competition.

On the positive side, there can be little doubt that consumers and firms will benefit from this transformation. Services will become faster, cheaper and be more reliable. But the changes also bring risks for the whole economy, especially for the labour market and, by extension, for social cohesion in modern economies. Some of the changes may drastically worsen job and wage prospects for low- and middle income groups. Already, there are apparent tensions and job angst in several countries stemming from globalisation and technological developments.

The transport sector represents a fairly large part of the labour market. In the US, there are about 1.6 million truck drivers alone. If other commercial vehicles are included, the onset of automation could affect a large group by reducing the number of jobs, change the nature of work as well as the wage prospects. The transport sector also represents the arteries in global value chains and so can have many indirect effects on the rest of the economy. With full automation the freight sector, notably through self-driving trucks, businesses along the transportation routes could also be affected, as software does not need coffee-breaks and refueling en route is faster and cheaper than human's restaurant - and no hotel visits are needed.

In this paper, I use the overall experience from structural change driven by technology in general and by digitalisation in particular to discuss the impact on the transport sector. The focus is on understanding the impact of automation the transport sector labour market and how it could affect jobs and incomes.

In my assessment, our economies are versatile enough to create new jobs in the long-run so that technology will continue to be benign for human work and welfare. It is undeniably the case that our economies have so far been able to adapt to a great many changes, moving from being primarily based on agriculture to mass production and the increasing dominance of services. In hindsight, all these changes have led to increased prosperity for all of society, but life was tough for many people amidst the upheaval. The economic historian Joel Mokyr noted that welfare did not improve much between 1750 and 1850 (see Mokyr, 2004).

Today, modern social safety nets and standards alleviate some of the burden of change on individuals and our economies have developed ways to share risks among groups and generations. Among OECD countries, Japan may be the only one where younger generations are not better off than older ones due to two decades of poor growth and the rapid aging of the population, combined with strong rights for insiders. ${ }^{1}$

Looking ahead, the challenge is that the path of structural change could include rather difficult periods of transition that have more resemblance with the initial disruption from the Industrial Revolution than with latter periods of more benign change. Notably, low-skilled workers in the transportation sector could be especially exposed.

There is no easy way to predict how large a challenge this will pose. The rate of change will depend on regulation and a host of other factors. But it is clear that retraining low-skilled workers and especially older workers - should be a priority. One way to summarise the policy challenge is how to allow the benefits of technological progress while limiting the potential negative downsides in the labour market. In terms of social welfare, the key challenge is how institutions respond to maintain incentives for innovation and job creation while not giving in to special interest groups and protectionism. 
This will present a precarious balance for policy. Unless handled well, technology may further widen the gap between insiders and outsiders, incumbents and startups. As a result, inequality could rise further and income growth be concentrated to a few "winners-take-all", who acquire much wealth, while others may work freelance and "on-demand" with more insecure and lower income streams.

It is important to stress that there is nothing inevitable about the welfare consequences in the years to come. The outcomes - good or bad - will depend on the choices of institutions and their ability to adapt to technology, demography, globalisation, and other factors. Indeed, a key insight from research is that nations that have managed to become rich have had institutional features that supported incentives for value creation while ensuring that the ways insiders and special interest groups can extract monopoly rents are limited (Acemoglu et al., 2005). The strongest driving force behind inequality is probably not technology, but the response of institutions when they erect barriers to entry, especially in the labour market.

The rest of this paper is organised as follows. The second section discusses microeconomic drivers for change that will have impact for the whole economy. The third discusses the historical experience of technology in the labour market, surveying the academic literature with particular emphasis on the transport sector. The fourth sector draws on that experience to discuss possible scenarios for the freight transport sector. The sixth section discusses some strategies to adapt and the final section concludes.

\section{Microeconomic drivers of change}

Economics at its core is about understanding incentives and tradeoffs between different choices and their implications for the economy and welfare. Digitalisation has not changed this but many other aspects of economics may be affected. I begin by discussing the features that affect the economy as a whole and illustrate the mechanisms with aspects concerning automation in freight transport.

\section{Higher speed of technological adoption?}

It is undoubtedly the case that technological diffusion is occurring faster. As can be seen from Figure 1, the time it takes for new inventions to spread across the world has declined significantly.

It is useful to have this long-term perspective in mind when we consider the impact of new technology. It is not enough to have a groundbreaking invention to have an economic impact. History is replete with fundamental breakthroughs that rely on a host of other factors to become successful (Johnson, 2014). Railway freight was introduced in the first part of the $19^{\text {th }}$ century but took about 80 years to be broadly adopted; trucks came in the late $19^{\text {th }}$ century but its spread was almost half that time, about 40 years. For each of the technologies in Figure 1, there are significant infrastructure needs that need to be in place to support the technology. Evidently, railways need tracks and the benefits of trucks require paved roads. But infrastructure on its own is not enough. For the markets to work with the new technology, people need to develop the skills to use the new tools and the legal infrastructure to ensure trust. Without these in place, technological adaption is likely much slower.

If the freight industry can take the step towards semi- or full automation on its commercial fleet with existing technology, adoption could be very fast. Several car and truck manufacturers already incorporate sensors and other equipment needed for self-driving in their vehicles. Thousands of hours of driving experiences with these vehicles have also brought the technology further along in maturity. In essence, self-driving vehicles are already in the physical - if not in the legal - world.

If the regulatory and legal requirements remain uncertain, especially on safety concerns, adoption could be slow and not represent such a quantum leap compared to the past. 
Figure 1. Mean time of adoption for new technologies (years)

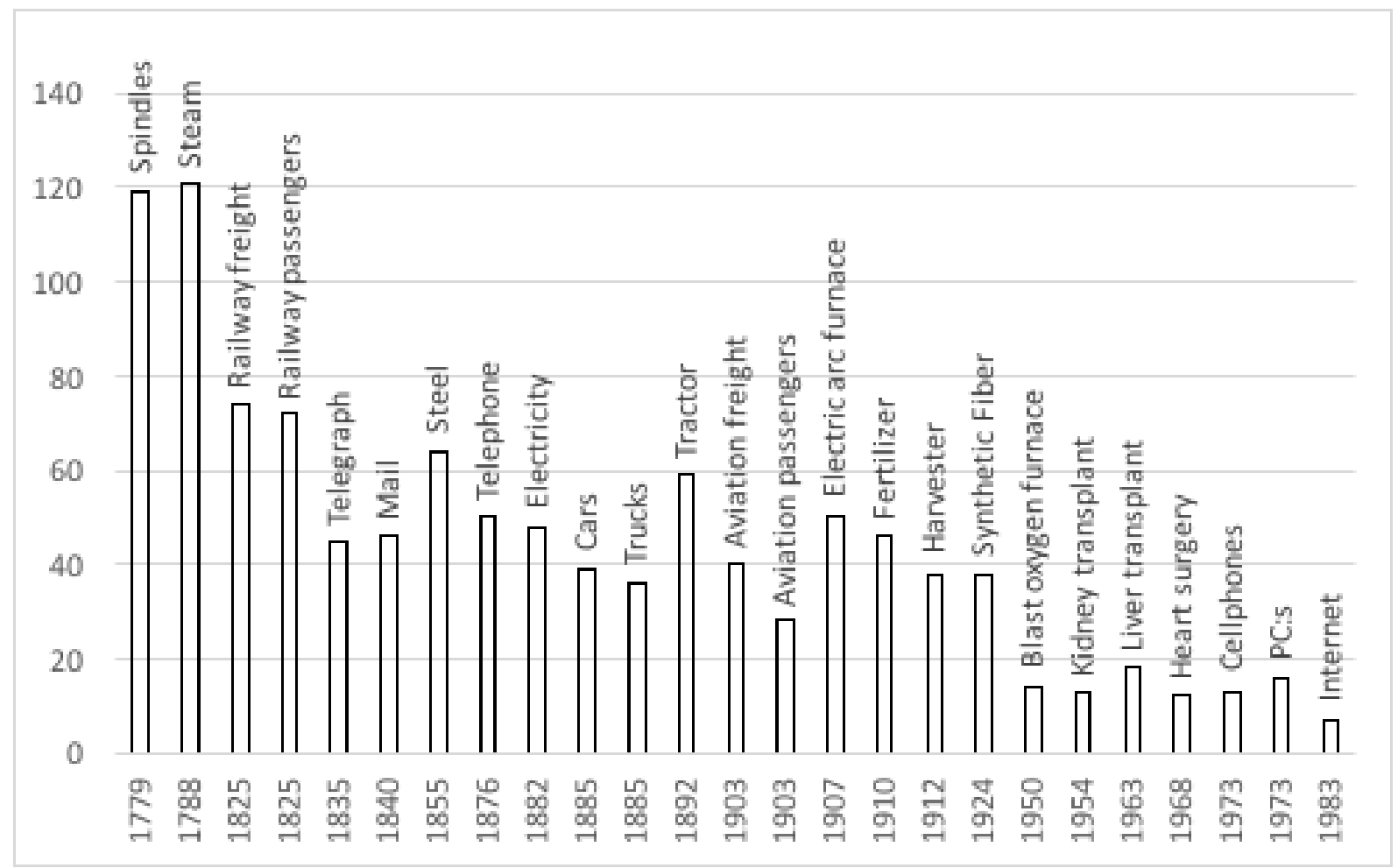

Note: The time to adoption is the mean number of years for a large sample of countries. Source: Comin and Mestieri Ferrer (2013, p. 14).

Another aspect that could slow down the adoption of autonomous vehicles is if the technology needs supporting infrastructure, for example from regulatory requirements or from better functionality. Paved roads have standards on separating lanes, traffic lights regulate the flow of vehicles and safety guidelines dictate speeds as well as other design. For self-driving vehicles, the equivalent infrastructure investments might be sensors in the roads, 5G-networks to communicate to servers and standards of communication between other autonomous as well as garden variety nonautonomous cars.

What this means is that it is likely the technology could be in place quickly but that there is nothing inevitable about the speed of adoption. It depends on regulation as well as on demand and supply effects.

\section{Network effects, demand and supply}

The most powerful aspect of how digitalisation affects the economy comes from network effects. Network effects have long been more of a curiosity in economics, with a solid footing in history books from the introduction of electricity and telephones. The difference with electricity is that digital technology can disrupt businesses more or less continuously: expanding the grid and lighting the way for modern appliances and factories, after which many of the steps were evolutionary rather than revolutionary. It has also been argued that digital technology is the only all-purpose technology that has increasing returns to scale (see Edquist and Henrekson, 2006). With the advent of digital technologies, network effects are coming center stage. The combination of an all-purpose technology with network effects are key to the development.

Autonomous vehicles are being made possible by a combination of mature "old" technology, such as sensors and cameras with powerful software. In and by itself, the software advances stem primarily from increasing speed of the hardware in combination with better code. Thus, the development of autonomous vehicles benefits indirectly from network effects that lead to better and more clever software. Instead of writing new code for all tasks, programmers can often find existing blocks of code, which speeds up the process of improvement. In addition, advances in neural networks 
and artificial intelligence (AI) also improve the software in ways that would be difficult to program directly. Moreover, the behavior of autonomous vehicles can be simulated in the computer and the response to various events can be tested in advance. In much the same way that financial regulators try to stress test the banks, software from autonomous vehicles can be tested and developed within a safe virtual environment.

To understand the interplay of different drivers for technology and automation in the economy, it is useful to divide the effects into those that affect demand and those that affect supply at the micro level: the firm or the individual. On the supply side, network effects, increasing returns to scale, and 3D printers are among the factors leading to faster, cheaper production.

On the demand side, increased price transparency and more global access are improving efficiency and competition. Digital platforms may be thought of as combining the elements of both improved supply and demand: by smoother matching of buyers and sellers they are creating markets and opportunities even for goods and services for which transaction costs and frictions were hitherto prohibitively expensive.

In Box 1, I give a stylised summary of the various channels through which digitalisation affects demand and supply. At the most basic level, it seems reasonable that people's preferences and attitudes to risk will not change due to digitalisation though they may change for other reasons over time. ${ }^{2}$ But digitalisation can change the exogenous factors that affect economic agents' decisions about work, leisure, trade, and so on. All of these channels have a variety of indirect effects on the macroeconomy, total output (GDP), employment, and inflation.

\section{Box 1. Summary of how digitalisation can affect the economy}

\section{Output (GDP)}

- Lower transaction costs

- Network effects and increasing returns to scale for digital goods and services

- Improved matching: digital platforms also enable minor transactions in goods and services

- Speed of technical diffusion increasing in some dimensions

- Non-exclusive nature of digital goods

- Lower cost of tweaking production/innovation.

\section{Capital}

- Many free digital tools available

- Cutting out the middleman reduces cost

- Cloud computing, vast processing power available

- Easier available capital with peer-to-peer (P2P) and peer-to-business (P2B) financing

- New payment systems; bitcoin, apple pay, swish, etc.

- More efficient use of existing capital stock (cars, apartments, tools etc.), sharing economy

- More seamless information

\section{Pricing power}

- Easier price comparisons and transparency

- Younger generations more prone to price comparisons online

- Easier entry

- Increased global competition in value chains

- More information about consumers and targeted advertising, price discrimination

- Brand names established faster but also higher risk of negatives

\section{Wages}

- Online labour markets services more global

- On demand economy and self-employment increase competition

- More self-employment may change wage-bargaining processes in the economy 
As can be seen from the box, technology is impacting on the economy in a variety of ways. In contrast to the situation about a decade ago, a number of key conditions have evolved and matured:

- The emergence of large platforms with standards that attract consumers and producers alike (the web, Apple with iOS and Google with Android).

- Trust mechanisms for digital transactions, both for goods and services.

- Digital payment systems with low transaction costs.

- Ubiquitous use of smart phones and tablets.

The world is becoming increasingly used to transactions in digital goods and services. So far the changes are mainly consumer-driven. Consumers search the internet, use their smart phones, and share information, pictures, and experiences, much of which has implications for commerce or social discourse. Successive generations are likely to increasingly use digital tools for consumption and leisure; this means that consumer-driven activism will remain a major force and may continue to increase in importance. Each new service only needs to be available in one of the major app stores and/or on the web to reach a large number of consumers.

The increase in all aspects that are digital is having effects also on production. The service sector has increased as share of the whole economy in most countries and digital technologies are further contributing to this trend. For example, self-check-out counters in shops reduce the amount of human work, similar to what can happen if commercial vehicles become fully autonomous. Digital technologies are changing many other aspects of supply in the economy, all from capital needs to production costs.

\section{Less capital needed for many digital companies and its implications}

Some of the first benefits of the Industrial Revolution lay in replacing manual labour by machines, known as "capital deepening." But once the major shift from a labour-intensive economy is made, productivity improvements from capital deepening become lower; that is, the marginal return from an additional unit of capital decreases over time. For OECD countries, most of the growth differentials in recent decades are explained by how well the productivity factors interact together in "total" or "multifactor" productivity (OECD, 2016b). Most of productivity growth is driven by a few frontier firms (Andrews et al., 2015).

Does digitalisation change the economic logic of the current shares of labour and capital? For some parts of the economy, notably manufacturing, digitalisation has involved a gradual shift over long periods of time. Fewer people have been needed to perform the same functions. As can be seen in Figure 2, the labour share of income has been declining. This development has occurred for 42 out of 59 industrialised countries where there is at least 15 years of data between 1975 and 2012 (Karabarbounis and Neiman, 2014). The labour share in the USA, for example, has declined to about $55 \%$ in 2012 compared to 58\% in 1975. While the result is not uncontroversial, it means that there has been a significant shift towards capital and machines at the expense of labour. Should the trend continue, it raises troubling questions for the labour market as it could herald further rising income inequalities.

Although the shifts in Figure 2 are significant, for those sectors involved in "digital production" the shifts have more effect on labour and the economy. The effects can be dramatic.

First, the amount of capital needed to start a digital firm is often much less than that of physical production. A moderately fast computer and an internet connection may be all that is needed. Platforms, software, storage, and computing power are free or can be rented at low cost. Powerful and sophisticated tools are available through cloud computing. One effect of this is that even small startup firms can swiftly become large based on very little capital. It is easy for small service firms to handle large volumes of clients with tools that automate tasks and that can be downloaded from the web.

Second, by using existing ICT platforms, "digital" firms can implement new business ideas and spread them very widely at low cost. For instance, Apple's app store is an example of an ecosystem where, with a modest amount of programming, it is possible to reach almost the whole 
world. It also increases competition for apps in a dramatic way, which can increase innovation and quality.

Figure 2. Declining labour share of income in selected industrialised countries

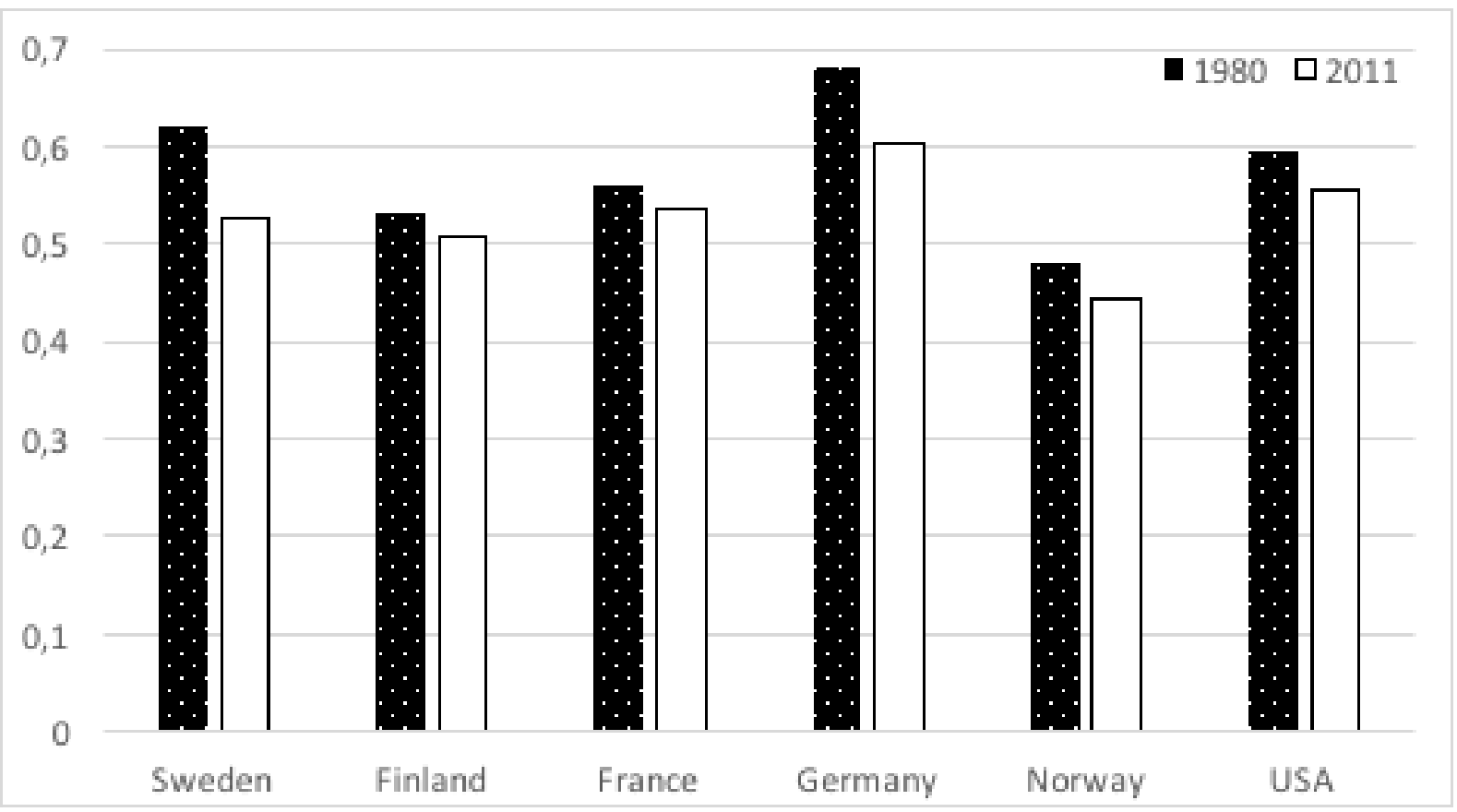

Source: Karabarbounis and Neiman (2014), https://sites.google.com/site/loukaskarabarbounis/research.

\section{Quicker production and cutting out the middleman}

Digital technologies make it possible to speed up production and improve quality. The initial stages of the Industrial Revolution entailed building specialised machines that performed one task and one task only. New products typically involved costly changes to existing machines or, indeed, the need to build new machines. As a result, product cycles tended to last longer than they do now.

Firms that have not updated their IT systems for a long time may find themselves suddenly facing intense competition from those that have modern platforms and are able to more clearly discern customer demand and adjust production accordingly. Banks are especially vulnerable in this regard with old IT platforms stemming from a combination of conservative upgrade cycles, legacy systems, and mergers. The same may hold true for shops and chain stores that use outdated IT systems, with vast potential for improvement. For the transport sector in particular, firms that use old IT systems may find that the market is shifting and that it becomes more difficult to respond. Auto and truck manufacturers are also seeing competition from firms that were initially focused on software solutions, with one example being Google's program for self-driving cars.

With advances in robotics, machines are becoming more versatile and reprogrammable, even in areas where highly skilled labour interacts with physical development - and so has broader relevance for the manufacturing sector. We are not yet at the point where machines can replicate the full range of human physical and cognitive skills, but in many sub-areas, computers consistently outperform people. Computers have won against the best chess player, the best jeopardy player and, more recently, against the best go player. Perhaps sometime in the future, the best Formula 1 driver will be a software program.

As robots become more programmable, the fixed costs become smaller and their uses increase. Architects are working on ways to send their drawings directly to industrial robots for production. When design can be sent directly to industrial robots, another intermediate function of production is removed, thus speeding up production and making it economically feasible to have smaller production lines, retooling more frequently, and making goods more personalised, similar to 
the advantages of 3D printers. This could potentially affect how trucks are built, concentrating production among a few companies and reducing the need for specialist suppliers.

3D printers are already being used to build bridges and houses. With complete design of a bridge in the computer, it is possible to reduce the amount of material used. In the example of the bridge, this resulted in $75 \%$ reduction in weight, which is a major cost saving only possible through software integration of design with the printer (Economist, 2015). The same cost savings could be possible in other production areas, such as in the production of trucks.

It is difficult to assess how far digitalisation has cut out layers of production and streamlined processes. The changes are occurring in broad sectors of the economy, including in areas hitherto largely unaffected, for example in the restaurant business. But even if the magnitude is so far unclear, the direction is not. During the Industrial Revolution, machines were replacing workers; today all sorts of functions, but especially those that are primarily rule-based are being increasingly automated.

Indeed, eliminating the intermediary has been a trend in many areas: word processing reduced the need for secretaries; online booking, the need for travel agents; and online banking the need for bank tellers. A recent example is InShared, a Dutch insurance company, that has recently made the whole claims process digital, thus eliminating several layers of human interaction. ${ }^{3}$ Fully autonomous vehicles might also lessen the need for intermediaries such as truck companies organising drivers. Truck producers might instead directly sell services in the form of access to their autonomous fleet which could be bought small or large firms or shops. With more aggregation of logistics, it is possible that the fleet of trucks comes to better use and less spare capacity is wasted. For example, trucks that return empty could be reduced if there was a better match of buyers and sellers of transport space.

Reducing the need for the intermediary has other direct production effects as well. A digital design can be changed more easily than a physical one. With few strokes on the keyboard, the initial design can be easily improved and production processes updated at low cost. This is good news for innovations. The possibility to experiment and explore becomes cheaper and easier; with 3D printers, designs can be shown not just in concept but also physically, which cuts costs in the sensitive start-up phase for companies.

I am not aware of any research that systematically analyzes how far intermediary services have been squeezed. Thus, it is also hard to say how much of efficiency and productive growth comes from this trend. But looking ahead, it stands to reason that digitalisation may bring further efficiency gains, especially in areas that have hitherto been less affected, especially in services, including highly skilled services in the professions.

\section{Changes to production: Physical goods becoming digital services}

Not only have services increased over time, digitalisation is increasingly transforming physical goods into services. So far it has affected books, movies, music and entertainment. For example, a book is a physical product, but can now be consumed electronically as an e-book. Moreover, instead of storing goods and spare parts, it will soon be possible to print all sorts of things with 3D printers, further blurring the difference between goods and services. This transformation is also leading traditional manufacturers to supply services along their products. Truck-manufacturers, such as Volvo, are offering their trucks for rent as an alternative to selling them. Another example is that peer-to-peer car sharing is becoming a new category of service as distinct from ownership, traditional rental or paying a taxi-driver.

Traditional production will also be affected. Vehicles are no longer just trucks or cars, they are essentially wheels that have been outfitted with big computers containing millions of lines of code. Commercial trucks have long been fitted with "black boxes" similar to airplanes. The data generated from the trucks can be used to control fleets, their location, speed, and so on. As a result, it may be possible to further cut costs of maintaining a fleet of trucks. Swedish companies Scania and Volvo have been supplying such services for a long time. ${ }^{4}$ The data can also be used for other purposes, such as giving feedback to drivers on fuel efficiency and "predictive maintenance," which can provide 
advance notice if the truck needs new spare parts or other service. Volvo estimates the time savings from the software at about 13 hours per month for a truck fleet of 40 vehicles. $^{5}$

\section{Subscriptions becoming more common}

Digitalisation is changing the calculus for how firms can charge money, notably in choosing between subscription-type services or payment per good or service. While it is hard to generalise, subscription services are associated with loyalty and steady revenues and are thus attractive for firms whenever possible. For example, newspapers and gyms traditionally offer both, but in rapid changing markets, businesses that are firmly entrenched in either model may also have to rethink their strategy or risk being left at the station as consumers jump onboard. Digital companies that initially provided a lot of content free of charge are tweaking their payment models in a variety of ways. This will affect traditional businesses in a lot of different areas, not least in digital media such as for music and books.

Some businesses are facing strategic choices about where they want their revenues to grow or how to find new ways to make money. Publishers that offer subscription services for books, music, and the like may be squeezed between consumers and content creators. Content creators want to be paid for each time their work is accessed, be it a song or a book. Thus, the more times a customer accesses a particular work, the less profit for the subscription service that charges a fixed fee.

It is not inconceivable that parts of the freight industry will begin to adopt subscription services. For example, groceries, furniture and other consumption goods that are transported on roads and rail could be delivered on-demand, thus reducing the need for intermediaries. This change could be driven by the logic of how subscription services have played out in other areas. With fully automated trucks, the business logic for such a change is potentially larger.

What this development will mean in the longer term is unclear. What is clear is that the relationship between the producer/content provider and the retailer/content creator is changing in complex ways and so are their relative bargaining positions. Much of the bargaining strength traditionally resides with the content providers. Also, the relationship with the truck producers and the retail sector could become stronger, as the intermediaries could lose ground.

Payments are also changing in other areas. Car rental firms are having to compete with providers such as Car2go that charge per use, which in turn may be competing with leasing alternatives and ownership. Facebook is providing newspaper content directly into the feed of its subscribers rather than sending customers to news sites via links. Netflix used to distribute content but is now successfully producing original material. Google used to be an internet-search company until it designed Android, its own operating system for smart phones and is now exploring venturing into cars, smart homes, health and other areas. Overall, digitalisation has blurred the line between production and distribution. Several companies are in the throes of deciding exactly what kind of business they are doing.

For businesses that are locked into a particular way of interacting with customers, it will be important to be able to change how it charges money in response to shifting consumer preferences and behavior. Firms that do not adapt to changing consumer demands on products or information risk falling behind.

\section{Technology and demography changing the labour market}

One conclusion to emerge is that the last few centuries of technological change have not, in fact, led to mass unemployment; that is, over time technological change has been neutral for the amount of work in the economy compared to the population. Moreover, there is strong evidence for so called complementarity between machines and human work, especially in the latter half of the 20th century: machines are improving worker productivity rather than reducing the total amount of human work (Autor, 2015). But, as we will explore in this chapter, there are some compelling arguments for why this might not be sustained during a period of transition in the coming years, looking one to two decades ahead. 
Even though long-run neutrality for technology and jobs is a reasonable starting position, it is not a law that holds true under all circumstances, especially not in the short to medium run. There are two reasons to be concerned about the pace of automation and its effects on labour:

- Digitalisation has broad effects on virtually all sectors at roughly the same time

- The changes today are much faster the previous technological disruptions

The first point makes digitalisation different from previous periods of structural change. The market economy is quite capable of shifting resources from waning sectors to waxing sectors but the challenge is greater when the driving force affects most of the economy virtually simultaneously.

The multi-shock challenge is compounded by the high speed of technological dispersion, currently much faster than previous technological disruptions, as illustrated in Figures 1 above: The labour market and our institutions may be too slow to adapt due to various frictions. A primary concern is that the pace of technological advance is too high for rather many persons in the labour market. When such a development persists over a longer time period, it increases job and wage polarisation. Consequently, wage inequalities could increase. Such effects of digitalisation on the labour market over one-to-two decades may be quite dramatic even if the year-on-year changes are small. It is difficult to predict the magnitude of the effects, but they are likely to depend on how firms respond and on how political institutions adapt.

\section{What is the impact of technology on jobs?}

Modern labour markets are complex and respond to many changes over time. To understand how technology affects jobs and wages, it is necessary to separate short-term developments from longterm trends. The academic literature in this area is large, but it is fair to say that there is agreement on the following points: ${ }^{6}$

- The first part of the Industrial Revolution was largely deskilling. Skilled labour decreased and was replaced by lesser skilled workers in factories.

- Latter periods instead exhibited an increased demand for skills. Wages, productivity and skills increased in many sectors and overall. There was strong complementarity between humans and machines.

- The last three decades have been characterised by job polarisation - the shrinking of the middle class - in many industrialised countries.

- At the same time, median wages for broad groups, especially in the US, have been stagnant. This has resulted in wage polarisation.

As the above summary spans centuries of economic development, it should also be clear that jobs and machines go through different phases. It is quite possible to have many years of difficult transition in the labour market, such as wage stagnation, even as the long run effect is positive for the economic standard, productivity and the income distribution.

It is a mistake to view the changes in the labour market as exogenous and without impact from policy. One strand of the literature emphasises the importance of institutions. The experiences from different OECD countries highlight that policy responses can have long run effect on how well the labour market can adapt to technological change (Acemoglu, 2002).

\section{Industrial Revolution was mainly deskilling}

Jobs performed by artisans moved to factories in the cities during the first phase of the Industrial Revolution. In this sense, there was deskilling in the labour market (Acemoglu, 2002; Acemoglu and Autor, 2011). The workers in the factories received lower wages than the workers they replaced. This disruption of income distributions came at time when political institutions were developing. There was considerable social upheaval. Famously, the so called Luddite movement took matters into their own hands and attempted to destroy machines. The political institutions reacted 
strongly and made such actions illegal. Although there was deskilling in parts of the economy, in some sectors and in the aggregate it did not happen (Katz and Margo, 2013).

\section{Job and wage polarisation has increased}

Unskilled workers have long had lower wage growth in the US. One explanation for the US is related to consumer behavior together with increased automation during 1980-2005 (Autor and Dorn, 2013). There were growing number of jobs as security guards, food operatives, assembly, and mining. For these jobs, wages were better than in lower level service jobs. One explanation is that jobs where robots work would be costly is still in demand, i.e. work where humans and machines are neither complements nor substitutes (Autor, 2015). For example, anyone venturing into a factory for cars will find many robots attaching parts, such as the windshield. But when the windshield is damaged, the work becomes mostly manual. It is not that it is not possible to have a robot repairing windshields. The issue is rather that the robot needs to be extremely versatile to handle all the different kind of vehicles that where repair is needed. A counterexample in this regard is automated carwashing, which for long have exhibited the kind of versatility that is necessary to handle many kinds of cars. The overall conclusion is thus that costs of automation vs. human flexibility is an important factor and that different jobs can at times be superseded by machines.

At the aggregate level, there is evidence in 16 countries for labour market polarisation during 1993-2010 (Goos et al., 2014). This has led to a decline in the size of the middle class in many countries (Vaughan-Whithead, 2016). Notably, in the US low skilled workers have also seen a decline in their real wages since the 1970s (Acemoglu, 2002). There is also evidence that US productivity growth stems mostly from reduced employment rather than improved performance in work (Acemoglu et al., 2014). For Norway, one study finds that access to broadband internet increases the wage bill share of skilled workers (Akerman et al., 2015).

Based on the Swedish experience, employment polarisation need not always be followed by wage polarization (Heyman, 2016; Adermon and Gustavsson, 2015). In Sweden, the labour unions' policy of high minimum wages in the collective bargaining agreements have prevented the development of a low-pay segment. Also, up until the 1990s the education system could support the high relatively high wage levels by focusing on skills and keeping the amount of unskilled work at low levels compared to other countries. As a result, Sweden has not experienced wage polarisation at the lower end. Instead, the insider/outsider problem with a two-tiered labour market has increased leading to greater insecurity for an expanding group of outsiders unable to find permanent employment (Blix, 2017). It has also lead to a rising shadow economy.

\section{Complementarity between jobs and machines?}

The experiences from the most recent decades has been much more positive in terms of how jobs and machines have evolved to affect wages and productivity. Humans and machines have by and large been complementary with each other. As machines have improved, they have in turn required workers with higher skills, which in turn has increased productivity and lead to a virtuous circle for the whole economy. While jobs have disappeared, the economy has been enough versatile to create new jobs in other areas, notably in the service sector. Even as technology destroys jobs, it creates new ones all the time.

The pace of change has been quick, but not as dramatic as during the first phase of the Industrial Revolution. Institutions and skills have been able to keep pace with the demands from the labour market. A large part of the structural change has led to a higher demand for higher education, in one study this is explained by $60 \%$ (Autor et al., 2003). Overall, there is wide agreement that skills became increasingly important during most of the $20^{\text {th }}$ century (Acemoglu, 2002).

The conclusion is thus that there has been strong complementarity between humans and machines in the last few decades, or so called skill-biased technological change (Acemoglu, 2002 and 2003; Autor, 2015). In practical terms, many of the jobs that have disappeared have been "bad", for example in being dangerous or physically taxing. For example, work in mines have long been known for their physically and mentally demanding nature. Today, much of this is replaced by robots and 
machines, often operated from the surface or even from far away. A similar development has occurred in other service sector jobs. For example, when ATMs were introduced, the bank tellers might have become superfluous. Instead, the jobs transformed to one of giving advice to customers (Bessen, 2015).

What does this experience suggest for the transport sector? What will happen to truck drives and other professional drivers if vehicles are fully automated? Or more specifically, will jobs in the sector decline in absolute numbers and require lesser skills? Or will the experience be more akin to that of ATMs? Further below, I discuss different scenarios for how the transport sector could evolve, focusing especially on the question of skills.

\section{Empirical estimates for risk of automation}

A new branch of the academic literature tries to estimate the probability that some tasks will be automated and hence the likelihood of jobs disappearing with a substitution from humans to machines. Typically jobs are assessed according to tasks, whether requiring mainly creative, repetitive, empathetic, or cognitive skills. Using statistical techniques in static context, the headline numbers indicate the probability that a robot or a computer may replace a human.

In a widely cited paper, Oxford researchers Carl Benedikt Frey and Michael Osborne argue that that almost half of the jobs in the USA today may be automated in the next two decades (Frey and Osborne, 2013). This has spurred estimates for other countries, including for Finland, the UK and Sweden. Most of the estimates are in the same order of magnitude, between 35-50\% for the whole labour market. A study by Melanie Arntz, Terry Gregory and Ulrich Zierahn argues that those estimates are much too high and finds numbers between 6-12\% for 21 OECD countries (Arntz et al., 2016). As far as I know, theirs is the only study that applies a consistent methodology across many countries. The lower results stem from considering tasks rather than job-categories and using the OECD PIIAC data set.

A selection of the results is given in Figure 3. As can be seen, the task based approach gives an-order-of magnitude lower estimates than the other studies. It should be noted that the studies address slightly different questions and it is therefore not surprising that the outcomes are not the same. One way to put the numbers in perspective is to compare the risk the overall churn in the labour market. For Sweden, one study puts the average job destruction at about $20 \%$ per year for the period 1990-2009 (Heyman et al., 2013). More specifically, during this time about 3.2 million jobs were eliminated and 3.4 million jobs were created, leading to a net growth in the number of jobs in Sweden.

Apart from the headline result that almost half of US jobs may be automated in the next two decades, some studies also give detailed probabilities for each profession. Frey and Osborne identify 117 out of 702 professions as having above $90 \%$ chance of automation, among them fashion models, library technicians, telemarketers, paralegals, manicurists and for drivers of commercial vehicles. A study on Swedish data identifies 14 such professions out of 114 Swedish occupations, including fashion models, numerical, library, and filing clerks, shop and stall salespersons, and assemblers. Drivers are close to the $90 \%$ of automation.

Indeed, a common result in the studies is the high risk of automation in the transport sector. In Figure 4, I display results from papers where both the overall risk of automation and the risk for transport sector is given. 
Figure 3. Empirical estimates for risk of automation in the whole labour market (percent)

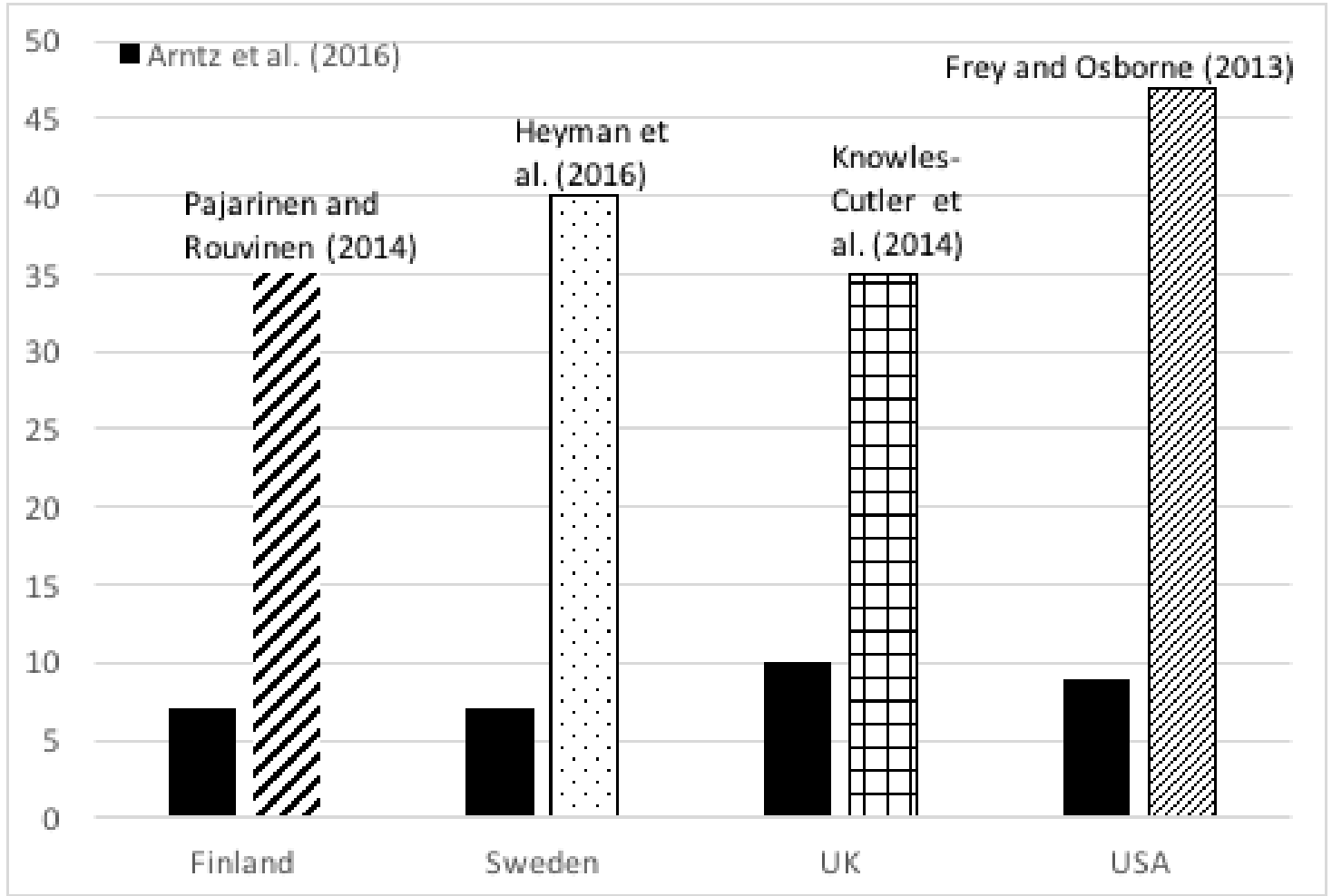

Note: The black bars are the estimates from Arntz et al. (2016). A comparison is made with different studies for respective country. For the UK, Knowles-Cutler et al. (2016); for the US, Frey and Osborne (2013); for Sweden, Heyman et al. (2016).

Figure 4. Selection of automation risks for the whole labour market and for the transport sector (percent)

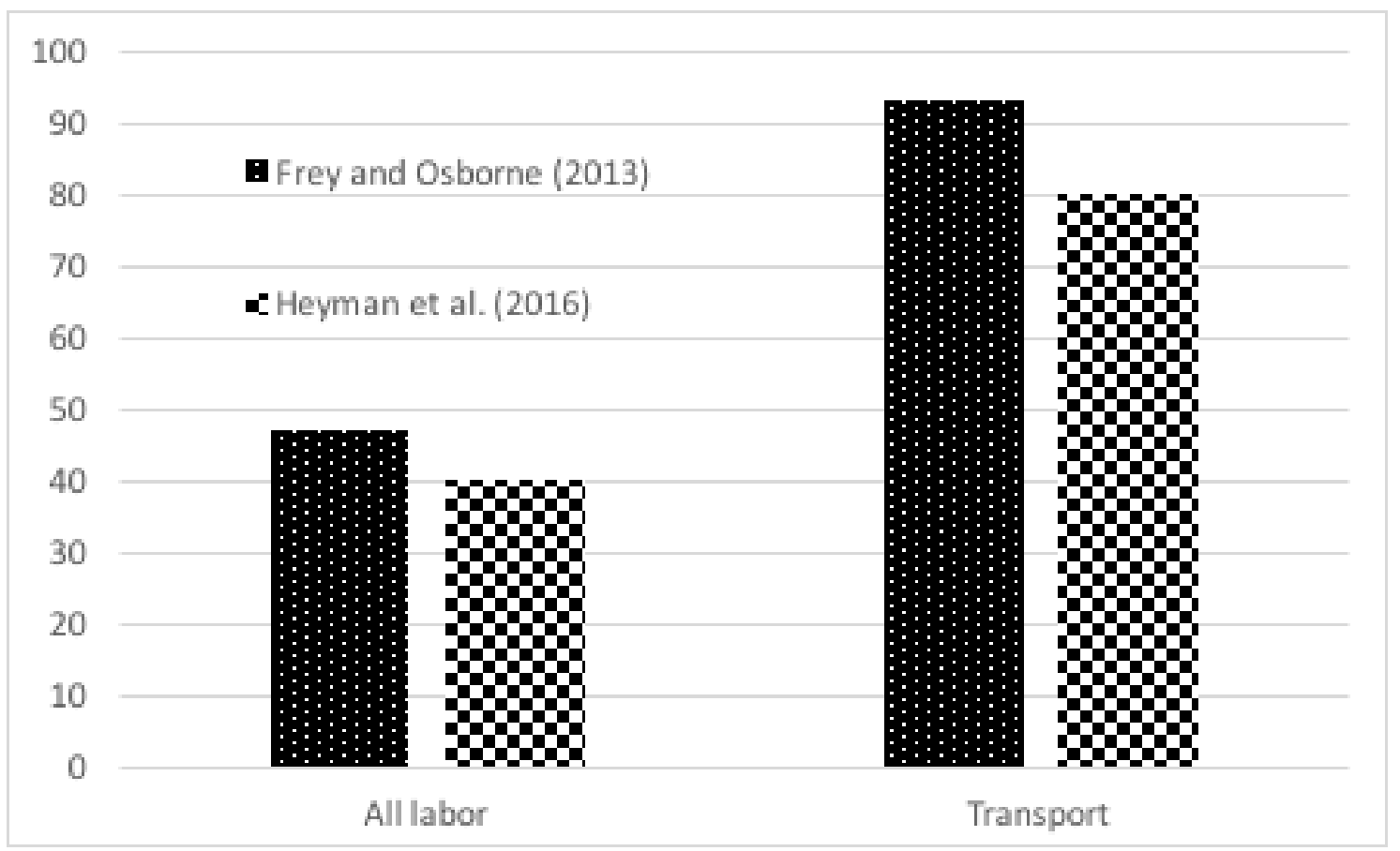

Note: Other studies that do not include the transport sector are excluded from this diagram; for those estimates, see above.

These models provide one way to address the risk of automation that is based on assessing the task according to categories but this is only a partial view of how automation may proceed. Below 
I discuss other factors that may be just as important, notably demography, regulation, and the costs of automation compared to human labour. Moreover, the analysis focuses only on job destruction even though we know from experience that new jobs are created all the time as a result of new technology and changing demand. For instance, personal trainers, professional computer gamers, hackers-cumdata-security engineers are all jobs that, not so very long ago, were either non-existent or very few. Job titles that might have appeared incomprehensible only a few years ago include tasks such as searchengine optimiser, data scientist or voice user interface designer.

\section{Decline in demand for skills over the past decade?}

All periods exhibit both substitution and complementarity between humans and machines. Looking ahead, a key question is what part of history will repeat itself. Could it be that the labour market enters into a period when substitution will dominate and there will be lower demand for some types of cognitive skills? There has been some recent work arguing that there is increasing evidence for a trend decline in the demand for cognitive skills in the US, which has resulted in downward wage pressures also on less skilled or unskilled workers (Beaudry et al., 2016). Another study uses detailed US O*NET occupational data for the period 2006-2014 and finds a significant reduction in skills that compete with machines and an increase in skills that complement machines (MacCrory et al., 2015).

\section{Labour market effects of future automation}

Despite hundreds of years of technological change, jobs have so far not disappeared. If someone had predicted in the $18^{\text {th }}$ century that almost all jobs in agriculture would be gone two-tothree centuries later, he or she would not have been believed. More importantly, such a forecast might have contained a very gloomy outlook for work and human development. The fact that we still have high degrees of employment is a powerful counterargument to fears that technology destroys jobs. The labour market is versatile, and as old jobs disappear, new ones develop.

MIT Professor David Autor argues that those who fear of automation underestimate two forces:

- The difficulty of automating tacit knowledge, i.e. things we can do without explaining exactly how, such as riding a bicycle or recognising a chair from thousands of pictures.

- The degree of complementarity between human and machine, that is, how technology makes us better at a wide range of tasks. (Autor, 2015)

Both of these arguments hold the key to future labour market effects of automation. They are also at the core of possible paths for the freight transport labour market. It is likely that in the long-run, human ability to adapt will create many new jobs even as old ones are automated. But what about the short-to-medium term? If the step from an economy based on agriculture to one based on manufacturing and services had occurred over decades rather than centuries, it is likely the changes would have caused large disruptions and social upheaval. Schools, institutions and rules in society adapt over time but with very rapid change, the conditions can alter to such an extent that it is difficult to change direction without incurring large social costs.

\section{Is tacit knowledge an obstacle for automation?}

The idea that tacit knowledge cannot be coded into software is an assumption and not a law of nature. The prime counterexample to advances in this area is from self-driving vehicles. Some years ago it was widely assumed that autonomous vehicles were impossible because driving includes too many elements of tacit knowledge where humans are superior. This proved to be wrong. Whether automation will in the future hit an insuperable obstacle when it comes to tackling tacit skills remains to be seen. Rather than being a brick wall beyond which automation cannot venture, tacit knowledge might be reshaped or subject to circumvention and redefinition.

Machine learning is a prime example of ways to avoid the difficulty of coding tacit knowledge. Machines can be taught to imitate and learn from humans and from observing physical events, and this an area of rapid progress and development. Developing vast sets of data, programs can draw inferences that are good and may prove better than human predictions in some areas. 


\section{Speed of change is a factor for the human ability to adapt}

There are three main arguments supporting a concern that the pace of change could outpace human ability adapt, at least for a period of transition:

- Adoption of technology is faster (see Figure 1), driven by Moore's law and network effects.

- The increase in temporary work and the rise of the gig work outside of collective bargaining agreements or without the same health care benefits of regular work.

- While life-long learning and re-training are available in many countries, they could be of insufficient magnitude when technological change is faster than in the past and life expectancy is increasing.

I discuss these in turn. Due to the longevity of Moore's law (Poeter, 2015; the Economist, 2016) of increasing computer speed, processing power is now so powerful that in many tasks previously reserved for humans, such as writing and research, computers are indeed faster and more accurate; increasingly, they can also write with style and it is no longer evident what is computergenerated or created from human hand (see Clerwall, 2014). While artificial intelligence is not in sight in the near future, software has become sophisticated enough to replicate humans in a vast array of areas, including highly skilled ones.?

Work can also be subdivided into smaller tasks and increasingly outsourced to gig work. There has been a general increase in the amount of temporary work in OECD countries (Blix, 2017, Chapter 4). More specifically, in the period 1990-2010, about $60 \%$ of all new jobs in OECD countries are non-standard, i.e. fixed-term, part time or self-employment (OECD, 2015a). Non-standard jobs account for about one-third of employment in OECD member countries (OECD, 2014a, Chapter 4); OECD, 2015a, p. 137). Over roughly the same period, work classified as largely has declined while abstract work and non-routine manual work have increased, see Figure 5.

Figure 5. Shifts in employment shares of different types of work (1995-2010)

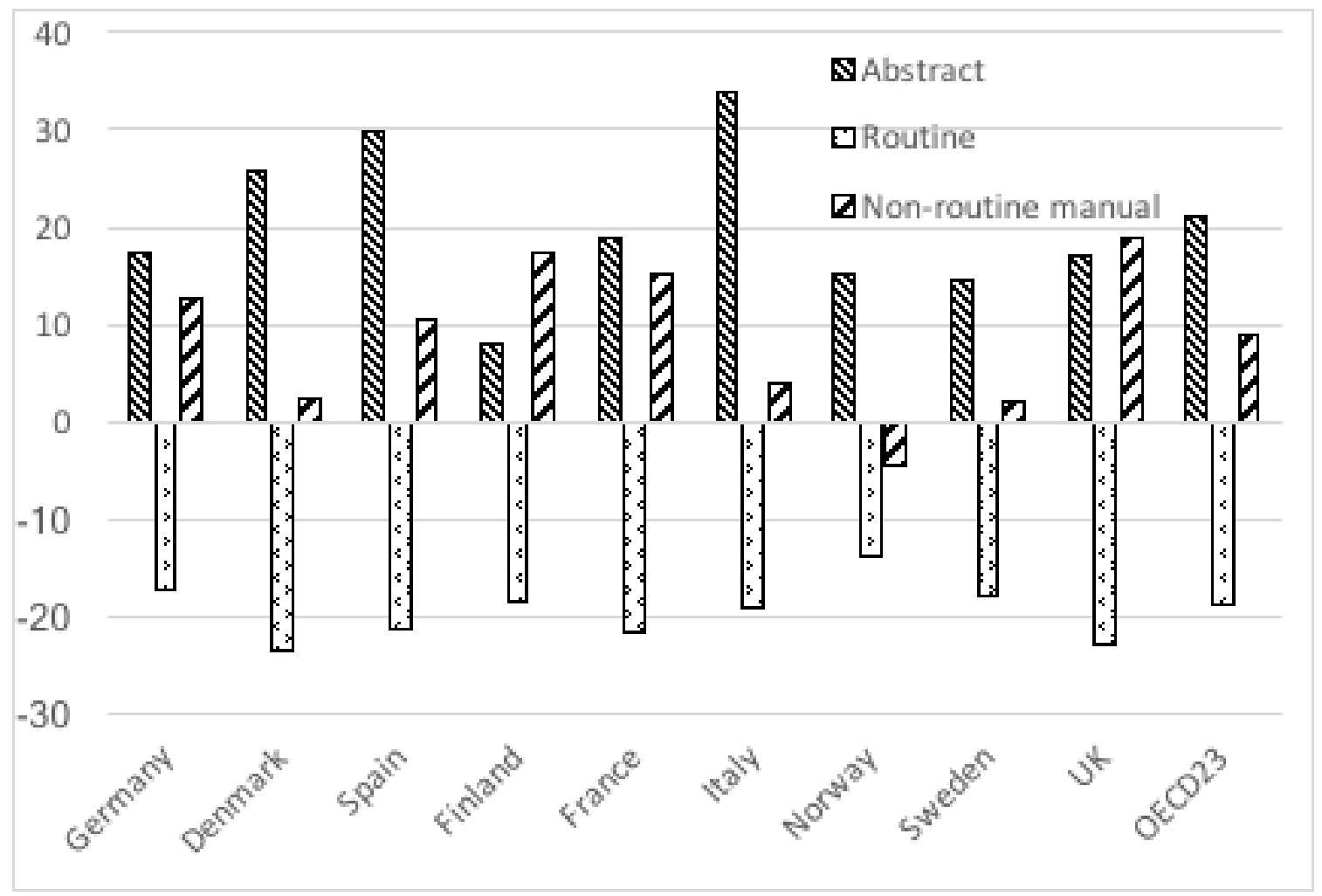

Source: OECD (2015a, p. 148). 
The nature of work is continuously changing but that process may accelerate with the advent of platform-based labour markets, such as Uber, Upwork and Etsy. Digitalisation is making it possible to match buyers and sellers also for small goods and services (Sundararajan, 2016). For some of these, competition is local, such as deliveries, car-services and household related services. Others are global. One example is upwork, where many tasks that can be performed on the computer can be done anywhere in the world, not least from low-cost countries.

As regards upgrading skills, the differences between those who devote time to retraining and life-long learning could be especially large when the pace of technological progress increases. There is already evidence of an increasing digital gaps in the work-place. According to a Eurostat survey, just under $40 \%$ of workers in the European Union judged their IT-skills to be sufficient to change jobs (OECD, 2014b, p. 89). Those with lower IT-skills are predominantly those with lower educational attainment.

\section{The labour market and the freight transport sector}

The transport sector directly employs millions of drivers. If other areas such as taxis, buses and delivery services are included, numbers are much larger. In OECD countries, there are typically between 3 to $6 \%$ of total employed working in the sector, see Figure 6. In the USA alone, about 1.6 million persons work as truck drivers, see Figure 7. The US Council of Economic Advisers estimate that between 2.2 and 3.1 million full time jobs in the US may be threatened in whole - or in part by automation, though not including new jobs that could be created (Executive Office of the President, 2016). The transport sector is not only a direct employer for many people but also directly affects work in many other areas, such as retail, insurance, hotels and restaurants. Drivers do not only deliver goods across cities and countries, they are also consumers of services along their travel. Regions that mainly benefit from tourism in off-seasons have the additional economic benefit of the spending from drivers on the road. Thus, a well-functioning transport sector supports the functioning of the economy both directly and indirectly. The indirect economic and labour market effects could be just as significant as the direct effects.

Figure 6. Employees in the transport sector as share of total employment (2014)

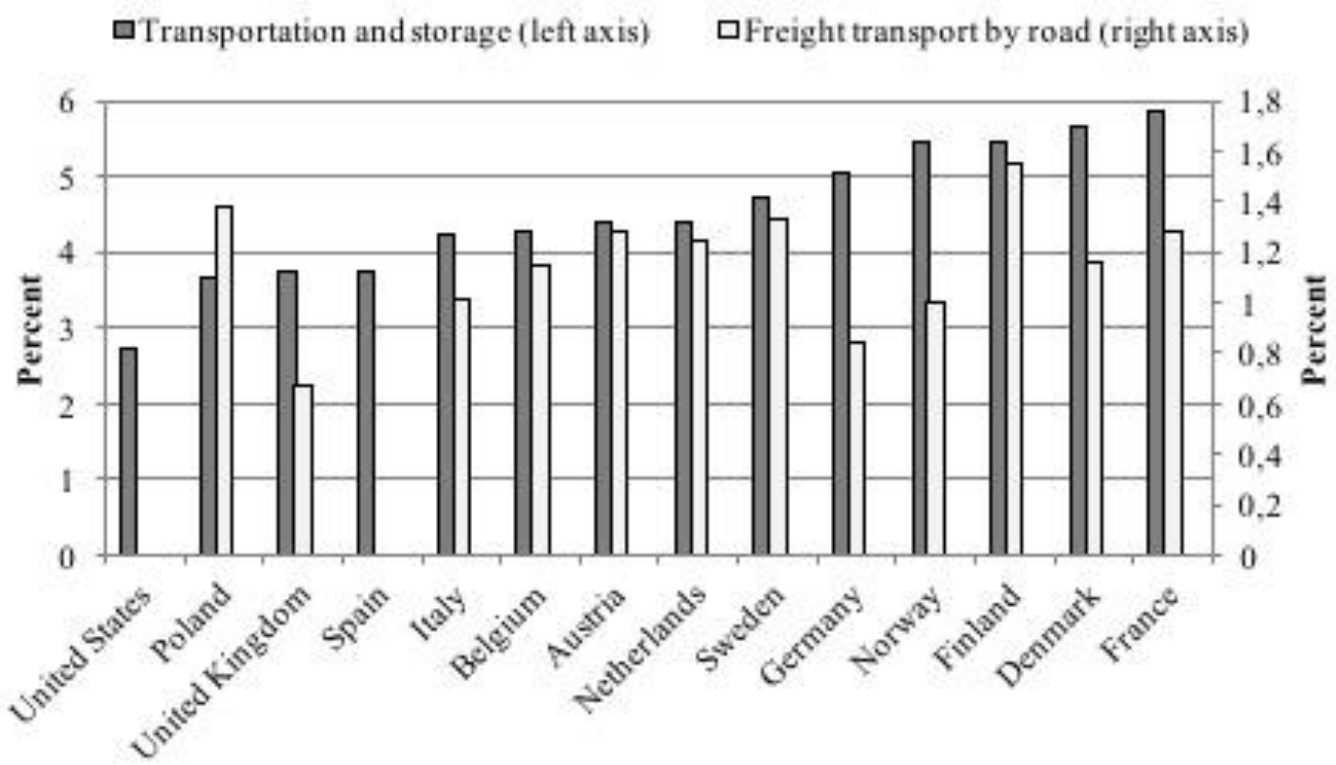

Source: OECD. 
Figure 7. Millions of employees in the US (2014)

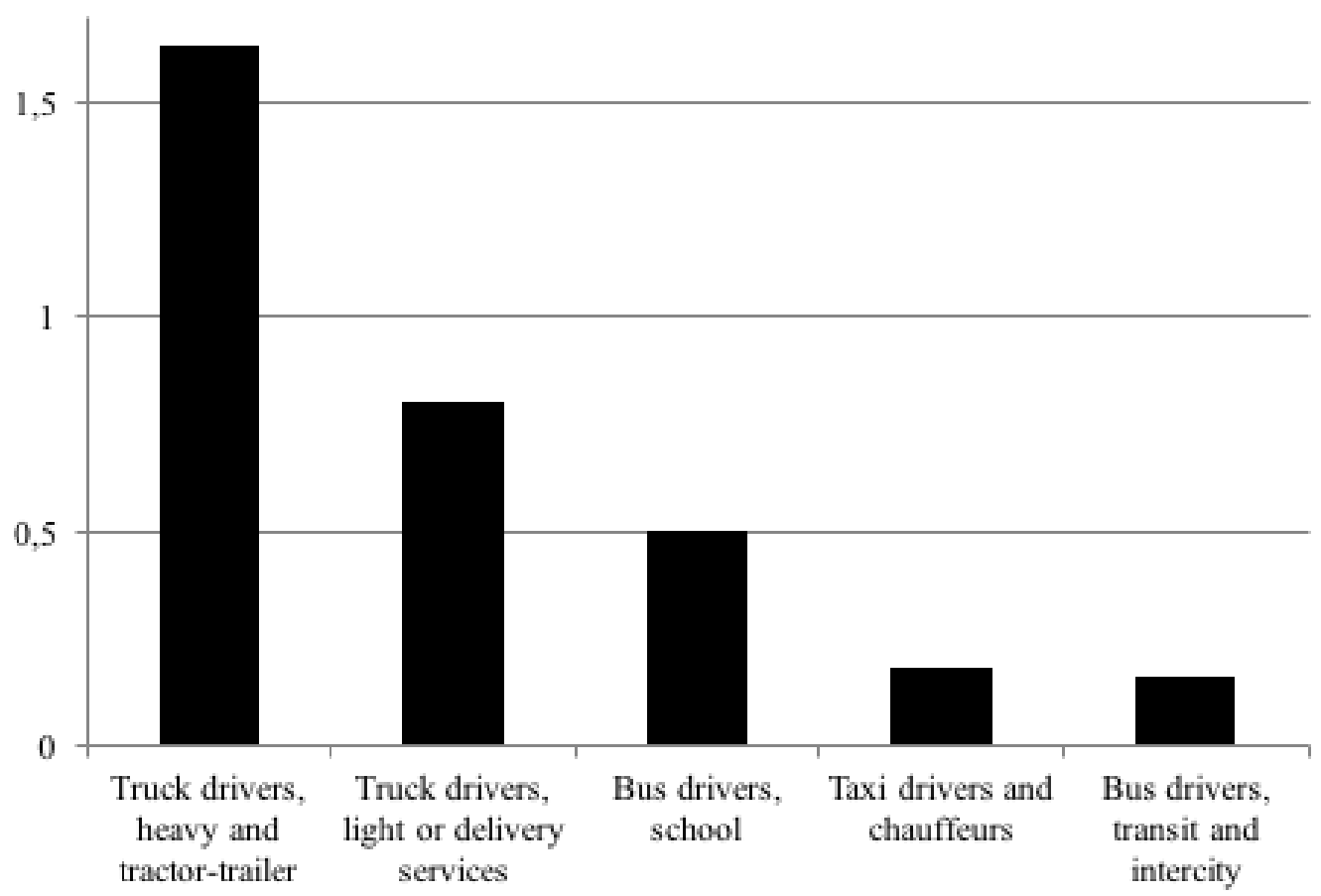

Source: Bureau of Transportation Statistics,

http://www.rita.dot.gov/bts/sites/rita.dot.gov.bts/files/publications/national_transportation_statistics/index.html.

The freight labour market is now subject to several interconnected developments that could have impact on employment and on the businesses, that support or rely on the transport sector. Three of these stand out:

- The development of autonomous vehicles, such as trucks, cars and drones.

- Platooning several trucks one-after the other to improve fuel-efficiency.

- 3D printing.

All of these technologies already exist and the issue is at what pace they will be adopted by the industry, which in turn will depend on how regulation responds (Ranft et al., 2016).

In the long run, 3D-printing technology could have significant effects on the demand for transport. It is already possible to print houses, bridges and tools. In the future, an increasing amount of products will be subject to 3D printing. Material for such printers will still have to be supplied but might be less bulky and easier to handle, which could lead to a relative reduction in the volume of transport as share of overall economic activity. It could also imply more standardised cargo than today. Once copyright, patent and safety issues are addressed, 3D-printers could reduce the need for some transport across large distances.

It is conceivable that some people will have 3D-printers in their homes, apartment buildings, or local neighborhoods. If someone wants a new household product, it might be printed locally instead of transported from afar. The same holds true for robots in the clothing industry, reducing the need for freight transport. When the step from design to product is reduced or eliminated, transport needs are lower.

Technologies for drones have also developed strongly and may increasingly compete with human deliveries. Amazon and other companies are exploring how far the technology can be used. 


\section{Overall factors that affect the degree of automation}

The labour market is complex. The technical possibility to automate work is only one of the factors that affect the amount and content of work. Other aspects that are important include:

- Regulation and safety requirements.

- Demography. In some sectors, tasks are increasingly automated because of the difficulty of finding skilled workers.

- Human preferences. Software can fly airplanes, but people may (for now) still prefer a human pilot who could intervene if needed.

- Costs of automation. Human labour remains cheaper for many non-routine tasks.

Regulation and safety requirements have both direct and indirect effects on the amount of work. In finance, for example, digitalisation is drastically reducing the number of tasks previously performed by humans, such as financial advice. But some regulation increases the amount of work, such as legal requirements in the banking sector. Complex regulation has led to more legal work.

Demography is a sometimes-underestimated force for automation in society. When there are not enough skilled workers available, the work either is not done or gets automated. Such outcomes are possible in, for example, sparsely populated regions or in expanding sectors. With aging populations, it may become increasingly difficult to have enough workers who care for the elderly or to replace workers going into retirement.

In some areas, a high degree of automation is already possible but is only partially implemented due to preferences for human labour. For example, passenger airplanes could already be flown by computers, teaching in classrooms could be done through interactive software where the teacher instead focuses on supervision, and robots can help the elderly with a range of tasks.

Finally, the costs of automation are a factor. Fitting a wind-shield in new automobiles is done by robots, but replacing a broken wind-shield remains a human task. The technology to have a versatile robot to repairs wind-shields is within reach, but is still likely prohibitively expensive compared to a human worker.

\section{Skill content and automation in the freight transport labour market}

How strong are the arguments listed above for holding back the speed of automation in the transport sector? Vehicles are already on the verge of becoming autonomous. Moreover, unlike for teachers, doctors and sales personnel, the preference for human interaction is likely to be lower. Indeed, incentives to reduce costs on human labour could be quite strong. One study argues that the economic benefits from autonomous vehicles represent 5.3\% higher GDP level in 2050, or about $0.15 \%$ higher growth per year (Ranft et al., 2016).

It is thus likely, that regulation will be one of the key factors that affects the amount of work in the transport sector. If one driver must accompany every truck, clearly there will not be much job reduction. On the other hand, the wages for those persons (no longer driving) are likely to develop poorly. Wages would likely be reduced. Why pay someone to accompany a truck for many hours when perhaps the only remaining work is loading and unloading?

The skill content of work is one of the most single important aspects that affect wage developments. If technology reduces the need for human skills, wages and prospects for work in the sector could decrease significantly. On the other hand, if higher skills are needed, wages could increase. In Box 2, I discuss scenarios for how work could develop in the transport sector. The ultimate outcome for the freight labour market will depend on the extent of de - or upskilling. 


\section{Box 2. Scenarios for the freight transport labour market}

The technology for autonomous vehicles is already available. The question for the future concerns the rate at which this technology will be adopted and what impact it will have on the demand for workers in the transport sector - and elsewhere. Another key question will be what skills will be needed once the autonomous vehicles become more wide-spread.

One upside with slower rate of adoption is that there is more time to adjust skills or for workers to change jobs. New workers will also enter the sector with updated skills as older ones retire, contributing to smoother transition.

On the downside, slower adoption of the new technology will lead to the productivity benefits of automation to be further away. This would dampen growth prospects for the economy as a whole and imply a competitive cost disadvantage. It is also conceivable that slow change could exacerbate wage polarisation and lead to stagnant median wages. In the long run, real wage growth should follow productivity growth and so lower productivity also has social costs.

\section{Choice of scenarios}

In some areas, the choice of scenarios is straightforward. For example, using an historical average of productivity growth is a natural starting points for macroeconomic assessments.

For the freight transport labour market, by contrast, it is much less evident what should be used as a benchmark. Since the change in question is the possibility of the current system with no (or limited) automation to one with ubiquitous and fully autonomous vehicles, it is not evident how to devise a baseline. Using akin to "a same-change" scenarios as above is problematic. We know that there will be a change but not what the effects will be. A more plausible option would be to use the rate of churn from some historical average from sectors that have undergone substantial change, such as the manufacturing or mining sector. This would be a useful approach in the context a fully developed model of sectoral re-allocation.

I have instead opted for scenarios based on the notion of different skill content of labour. While this is somewhat abstract, it has the advantage of being fairly directly related to the academic literature discussed above. There is overwhelming evidence that routine that jobs require lesser skills are being automated and that this results in job and wage polarisation. Intuitively, if a job requires lesser skills over time, employers have less reason to pay well, thus likely leading to slower - or even no - real wage growth.

\section{Medium skill, medium autonomy}

The least disruptive scenario for the transport labour market is one when the share of fully autonomous vehicles is limited. This can happen for a variety of reasons, for example, if regulation presents hurdles that are costly to overcome or in situations where human flexibility is more cost effective than multi-purpose automation. The experience from the labour market as a whole is that manual non-routine jobs are much less subject to automation.

Perhaps it will be possible to automate loading and unloading of cargo at specialised stations at or outside cities. But even so, many transports have final destinations in places inside cities where full automation could prove costly.

\section{Low skill, high autonomy}

A low skill scenario under high automation can be thought of one where a large share of the current tasks is still performed by humans, but the skills needed to perform the tasks are lower. For example, a human driver is less able to keep the same speed of the optimal speed for fuel consumption compared to machines. Software can calculate the most fuel efficient driving in ways that are impossible for humans. Such technology is already available in commercial fleets today and when fully implemented, further reduces the need for human driving.

In this scenario, human work will be concentrated around non-routine work that is costly to automate. Some work in the sector will even require higher skills than today. For example, repairing machines and vehicles could require a combination of software skills as well as understanding of mechanics. But 
diagnostics and communication technologies also imply that those possessing higher skills may not need to be on-site. In the same way that specialised doctors can follow a surgery on video-link from afar, contingency work and repairs on vehicles could also be done from off-site in combination with lower skilled labour.

\section{High skill, high autonomy}

If the freight transport labour increasingly goes towards automation, the decline in the amount of jobs could be similar to how jobs in the manufacturing industry have declined over time. Due to network effects from digital technologies, the changes could be much more rapid than before.

The driving forces behind a decline in jobs could stem from:

- Substantially better safety records than human drivers

- Lower labour costs.

- Less traffic congestions if transport logistics improved and vehicles also drive during the night.

There is controversy about the safety of autonomous vehicles and especially about the ethical and moral choices that must be programmed in advance. There is less controversy that the total amount of accidents could be substantially fewer. An established track record of better safety could lead to an accelerated impetus for automation

As regards labour costs, a human on board a fully autonomous vehicles with a solid track record would be rather expensive. If there is very little for the driver to do, such jobs will remain mainly if regulation requires it. In combination with platooning, one could consider one driver accompanying several trucks. The labour cost of one driver servicing several trucks could still be cost effective. Of course, in a platoon with five trucks, only one driver might remain employed.

Acceptance for autonomous trucks could also increase if transports were made off-peak hours, such as during the nights, thereby alleviating daytime congestion. Better logistics and use of existing capacity would reduce costs of congestion.

The ultimate effects of work on the freight transport labour market are likely to a large degree depend on the skill level of the jobs. A fully autonomous fleet will require a few specialised and high skilled workers to operate, but the amount of less skilled work could decline dramatically.

The most well-known example of deskilling comes from the first phase of the Industrial Revolution (see above) when the work of artisans were replaced with machines in factories operated by humans. The workers had lower skills and earned less than the artisans.

An illustration of the opposite effect comes from banking. When automated teller machines (ATMs) were introduced, there was a fear that the job of cashier would disappear. Although this occurred, this task became transformed over the years. Instead of supplying notes and coins (a rather menial job) the focus became one of giving financial advice, a job requiring higher skills and typically associated with higher pay (Bessen, 2015).

\section{More focus on life-long learning and upgrading skills}

People are living longer than before, yet the norm of spending the early years of life in education with comparatively less resupply of formal schooling in mid-life is persistent. With rapid advancement in technology, there is a need for a more systematic replenishment of knowledge throughout our lives. With an upgrade cycle of new models and software every year or every other year, the changes appear to be incremental. But over a longer period of time, such as a decade, the accumulated changes are large and require substantially higher skills. Without requisite improvements in skills, wage polarisation and inequality will likely increase, or in the words of Tyler Cowen (Cowen, 2015, pp. 4-5): 
Are your skills a complement to the skills of the computer, or is the computer

doing better without you? Worst of all, are you competing against the computer?

While skills supply is crucial to firms, "more" education is not necessarily the answer. ${ }^{8}$ Notably, one year in education is also one year not in work, which puts additional burdens on financing social welfare systems that were designed in times with a more favorable ratio of working to retired people.

Instead, we need education and skills that are in demand in the labour market to improve the matching between vacancies and jobseekers. One in four firms in OECD countries report having trouble finding enough skilled workers (OECD, 2015b, pp. 30-31). At the global level, one study reports mismatch between jobs and skills covering about $30-45 \%$ of the adult population (MGI (2015). Crucially, we also need ways to replenish that knowledge throughout life, not only so that we keep abreast of technology but also so that we are equipped to switch careers in mid-life as markets or preferences shift. ${ }^{9}$

For those with rudimentary skills, it is likely that even fairly small skill improvements can make a big difference for employability and wage growth. For example, one can argue that drivers of modern commercial trucks need higher skills than in the past to be able to use the full benefits of modern technology. Research from other areas, notably platform-based labour markets, shows that even minor improvements in skills and reputation can have a positive effect on earnings (Agrawal et al. (2015).

There are two distinct challenges. First, how can improvement of skills be better organised to cater to the needs of firms? Second, how should it be financed? The incentive for firms to finance learning for its staff is dented by the risk that employees may leave and take a job elsewhere, taking their new skills with them, but this is also the kind of agility required for efficient functioning of the labour market.

As regards the organisation of learning digital skills, the public/private UK Tech Partnership is an example of model that might be useful for other countries to consider. With a relatively small staff, the Tech Partnership coordinates education needs in existing firms through co-financing shared by government and business. They also focus on improving digital skills in schools, and especially on increasing the participation of girls. ${ }^{10}$

Experience from Norway shows that access to broadband internet increases polarisation by increasing the wage share of skilled workers. This suggests that to reduce inequalities, it is imperative to address knowledge gaps in traditional fields first, notably in mathematics, writing and science (OECD, 2015d). Another key lesson is that improving digital skills is not a matter of spending more public money, but how that money is spent. More subsidies for disadvantaged groups need not lead to an improvement in skills (Vigdor and Ladd, 2010).

To the extent that digital skills should become part of our general toolkit in the same way as mathematics and science, there are arguments that the public sector should finance some aspects, especially those that are more general in nature. An increased amount of public spending on life long learning adds to existing fiscal burdens, but could be very beneficial over time if it leads to longer working lives. This is especially true in countries with considerable public spending on welfare for the elderly where the funding for that expenditure is levied on a shrinking working population. Funding for life-long learning and for changing jobs can also come from directly from the labour market, as is the case in some countries. ${ }^{11}$

When more subject or firm specific skill are needed, there are stronger arguments that the financing should come from the private sector or directly from individuals. Where to draw the line between public and private funding of increasing skills is difficult question, but the issue is well worth pursuing.

More lifelong learning in appropriate doses is also likely to benefit productivity growth and make it less likely that people who stay in their jobs for a long time will become unemployable 
elsewhere in the event of company restructuring. A better system of upgrading skills and financing life-long learning would go a long way to smooth the social costs from rapid technological change.

\section{Reducing labour market risks for the self-employed}

As discussed above, structural trends in the labour market have led to an increasing amount of non-standard work that is almost always subject to fewer benefits and larger income uncertainty (OECD, 2015a). The driving forces behind this change has been a combination of institutional changes, aging populations and technological change.

In many OECD countries, the strictness of permanent labour market contracts has not changed much since 1990 but the protection for temporary contracts has been reduced, see Figure 8 .

Figure 8. Change in index on employment protection legislation (EPL) (1990-2013)

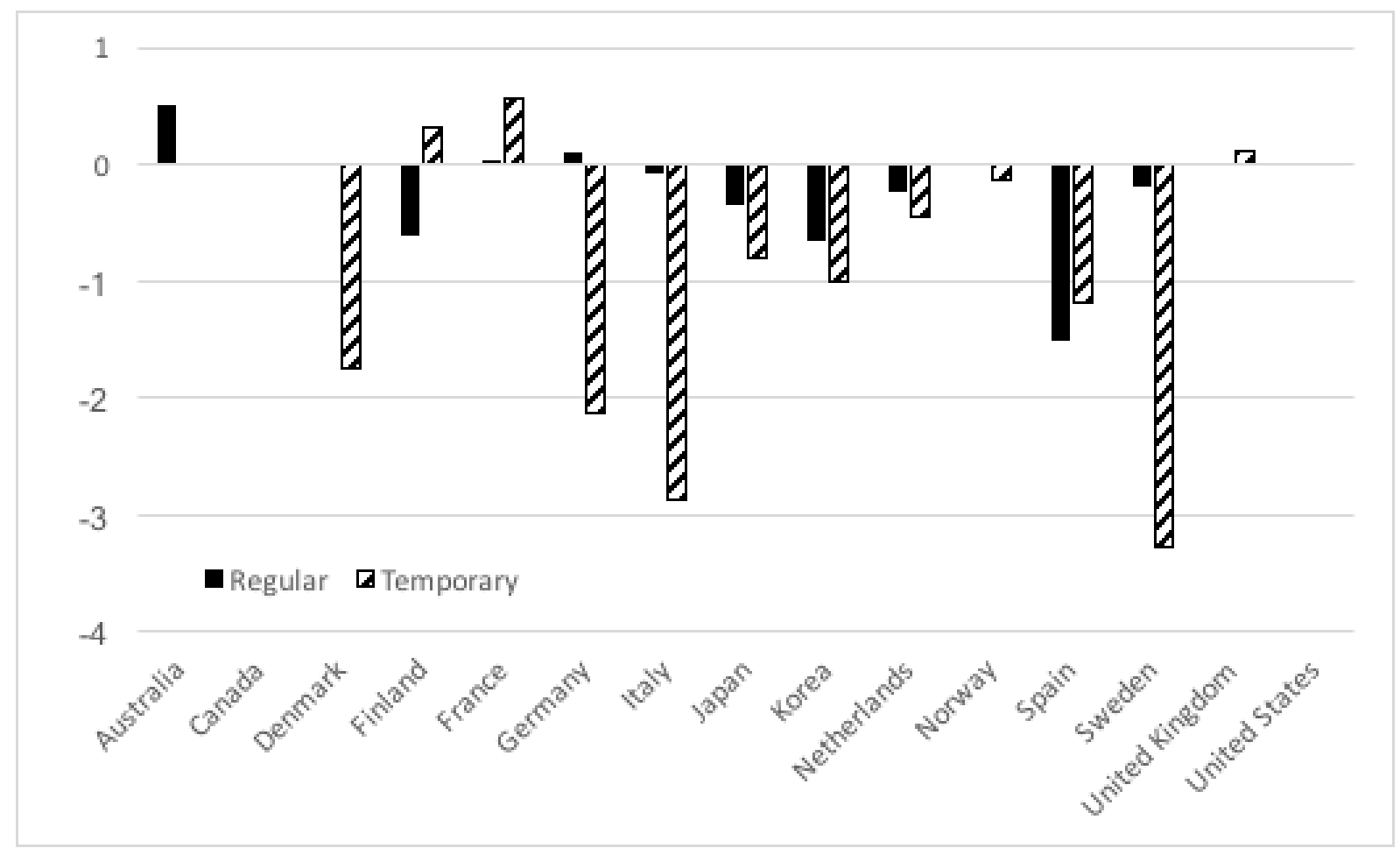

Note: The OECD classifies the strictness of employment legislation on a scale of 0 to 6 , with higher numbers representing more strict protection. The bars show the change in legislation from 1990 to 2013, with a negative number indicating reduced protection. The following countries have no change for permanent contracts (and hence no bars are displayed): Canada, Denmark, France, Norway, UK and the USA; for temporary contracts, the following countries have no change: Australia, Canada, and the USA.

Source: OECD, https://stats.oecd.org/Index.aspx?DataSetCode=EPL_OV.

Reduced employment protection for temporary contracts together with increased automation has changed the nature of the labour market. Digital technologies are making it easier to hire work on a temporary basis. Of course, it is natural to have a temporary job in the first years of entering the labour market. But the data is showing a structural shift in that young persons entering the labour market are to a greater extent on temporary employment compared to earlier generations, see Figure 9. What this means is that the dual nature of the labour market is increasing in some countries, thereby strengthening the insider/outsider differences in job and income security. 
Figure 9. The young increasingly in temporary jobs: 15-24 years old as share of total dependent employment

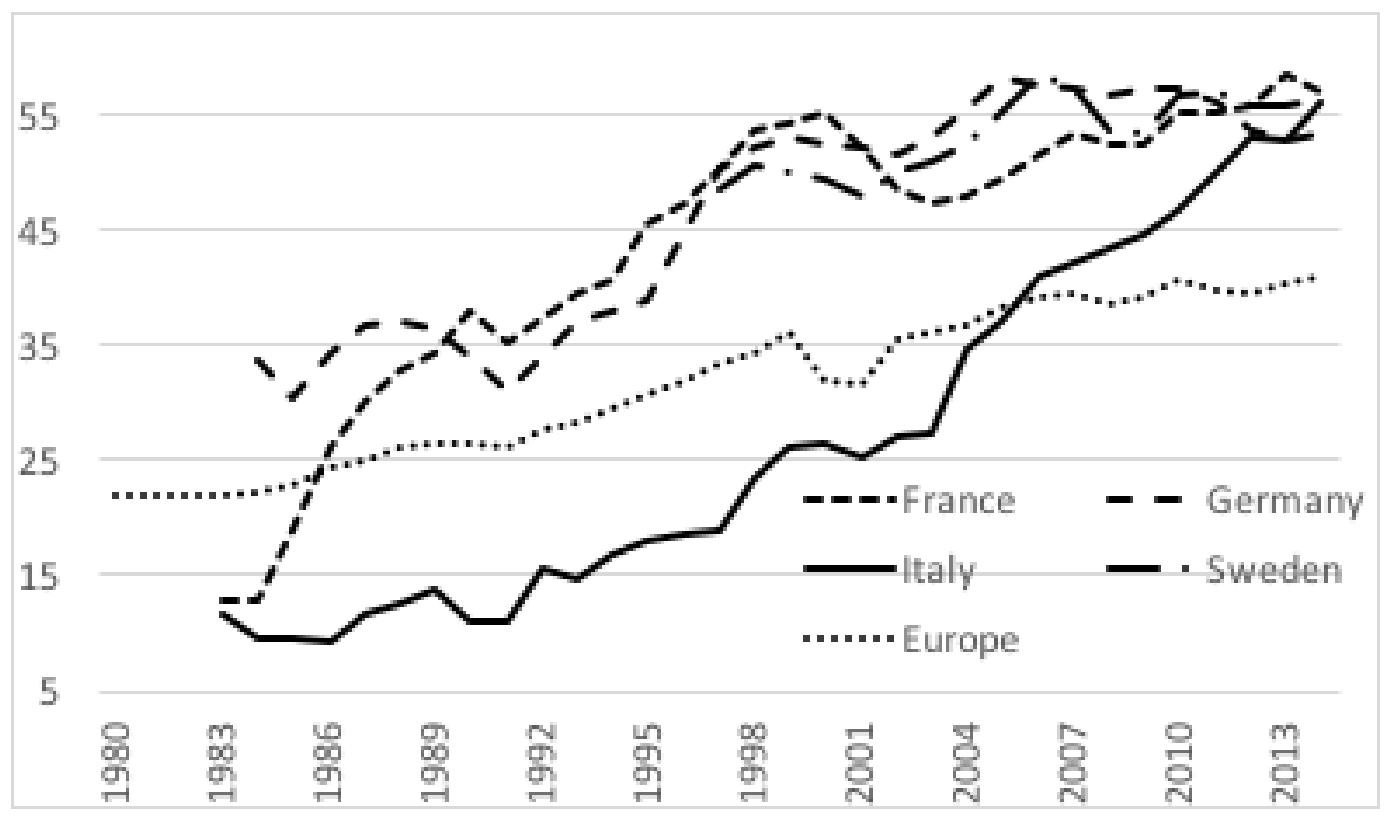

Source: OECD, https://stats.oecd.org/Index.aspx?DataSetCode=TEMP_I.

While the trends in employment have been underway for a long period, the recent financial crisis has exacerbated developments. Incomes for older generations were mostly spared as pensions were not reduced in OECD countries, but for many young finding a job in the aftermath of the Great Recession was difficult (Eichhorst et al., 2016). The number of youth not in employment, not in education or training (NEET) has increased significantly and was about 40 million persons in 2015 in the OECD as a whole (OECD, 2016a). Evidence shows that those with lower skills, especially those with unfinished lower secondary education or born abroad, are particularly vulnerable.

The new world of work with temporary contracts, more self-employment and platform-based labour markets have two main effects. First, incomes become more uncertain. And, second, labour market entry becomes easier. The latter development has mainly positive sides. Experience shows that those who are unemployed for a long time risk eroding skills and self-confidence, thereby further reducing the chance of employment. In this way, platform-based labour markets can become a springboard from education or unemployment to the labour market. There is already some evidence that this is occurring (Hall and Krueger, 2015). It can also make it easier to switch jobs between sectors or to supplement income. It can also help immigrants to enter the labour market and thereby reduce the risk of inactivity traps. A policy to make work in platform-based labour markets easier would thus improve the labour market outlook considerably. The main elements of such a policy include:

- A review of what standards that balance safety concerns with innovation.

- A tax treatment across activities that does not hinder entry but also not put existing businesses at a disadvantage. Specifically, where should the line be re-drawn between amateur and professional activities?

- How to apply social safety nets and benefits from collective bargaining agreements to the selfemployed?

The first two of these questions are outside the scope of this paper.

As regards social safety nets, one particular concern is that the difference between employment and self-employment is rather large, see Table 1 . In many countries, the safety nets are designed around full time employment at one institution or firm. People working freelance as selfemployed or in small companies do not fit easily into this box. 
Table 1. OECD assessment of statutory difference benefits permanent, temporary and self-employed

\begin{tabular}{|c|c|c|c|c|c|c|c|c|c|c|c|c|c|c|c|}
\hline & \multicolumn{5}{|c|}{ Part-Time } & \multicolumn{5}{|c|}{ Temporary Worker } & \multicolumn{5}{|c|}{ Self-employed } \\
\hline & ODS & SM & WI & UB & $\mathrm{FB}$ & ODS & SM & WI & UB & $\mathrm{FB}$ & ODS & SM & WI & UB & $\mathrm{FB}$ \\
\hline \multicolumn{16}{|l|}{\begin{tabular}{|l} 
Australia \\
\end{tabular}} \\
\hline \multicolumn{16}{|l|}{ Austria } \\
\hline \multicolumn{16}{|l|}{ Belgium } \\
\hline \multicolumn{16}{|l|}{ Canada } \\
\hline \multicolumn{16}{|c|}{ 姍册册 } \\
\hline \multicolumn{16}{|c|}{ Crech Republic } \\
\hline Denmark & & & & & & & & & & & 尾曲册 & & \#曲 & & \\
\hline \multicolumn{16}{|l|}{ Estonia } \\
\hline \multicolumn{16}{|l|}{ Finland } \\
\hline \multicolumn{16}{|l|}{ France } \\
\hline \multicolumn{16}{|l|}{ Germany } \\
\hline \multicolumn{16}{|l|}{\begin{tabular}{|l|} 
Greece \\
\end{tabular}} \\
\hline \multicolumn{16}{|l|}{ Hungary } \\
\hline \multicolumn{16}{|l|}{\begin{tabular}{|l|} 
Iceland \\
\end{tabular}} \\
\hline \multicolumn{16}{|l|}{\begin{tabular}{|l|} 
Ireland \\
\end{tabular}} \\
\hline \multicolumn{16}{|l|}{\begin{tabular}{|l|} 
Israel \\
\end{tabular}} \\
\hline \multicolumn{16}{|l|}{ Italy } \\
\hline \multicolumn{16}{|l|}{\begin{tabular}{|l|} 
Japan \\
\end{tabular}} \\
\hline \multicolumn{16}{|l|}{ Korea } \\
\hline \multicolumn{16}{|l|}{ Luxembourg } \\
\hline \multicolumn{16}{|l|}{\begin{tabular}{|l|} 
Mexico \\
\end{tabular}} \\
\hline Netherlands & & & & & & & & & & & & & & & \\
\hline New Zealand & & & & & & & & & & & & & & & \\
\hline Norway & & & & & & & & & & & & & & & \\
\hline Poland & & & & & & & & & & & & 耝 & & & \\
\hline \begin{tabular}{|l} 
Portugal \\
\end{tabular} & & & & & & & & & & & & 䎴 & & & \\
\hline Slovak Repub & & & & & & & & & & & & & & 巴曲册 & \\
\hline Slovenia & & & & & & & & & & & & & & 巴冊册 & \\
\hline Spain & & & & & & & & & & & & & 冊 & & \\
\hline Sweden & & & & & & & & & & & & & & & \\
\hline Switzerland & & & & & & & & & & & 艮册曲曲 & & & & \\
\hline Turkey & & & & & & & & & & & & & & & \\
\hline United Kingdo & & & & & & & & & & & & & & & \\
\hline United States & & & & & & & & & & & & & & & \\
\hline Pattern code & & no benefit & & different & $n$ stand & & \#曲 & ptiona & Iment & & No differen & to stc & rd work & & \\
\hline
\end{tabular}

Note: ODS is Old age, disability and survivors; SM is sickness and maternity; WI is work injury; UB is unemployment; FB is family allowances.

Source: OECD (2015a, p. 181).

The issue is not that the risk of being an entrepreneur should be taken down to a lower level, closer to that associated with being an employee. Self-employed people take higher risk for a variety of reasons, such as being driven by an idea, preferring more freedom, or seeking the rewards that can come with success. The issue is rather that the asymmetry between self-employment and being an employee is particularly large in many countries. The self-employed often pay into social security to qualify for the universal safety net, but are not able to draw on those benefits to the same extent because the entire structure is built around employee status, with all the concomitant rights and benefits (parental leave, paid vacation, additional pension rights, job security). Due to the nature of business commitments in small firms, self-employed people are less able take sick days or parental leave since there may be no one else to take up the slack. The effects on the bottom line might be lower profits or indeed endanger the long-term viability of the firm.

The same holds true for parental leave. Self-employed people can, in theory, be on parental leave on weekdays, perhaps with some limited work in the evenings, and try to catch up on work during the weekends with some help, e.g. from a spouse, but then they get lower benefits. Notably, the lower number of self-employed women in some countries could be due to the asymmetry between employee vs self-employed status in social security.

There are also other differences that may be significant, especially for newly started businesses. The boundaries between self-employment, employee and small incorporated firms would need to be better defined but this is difficult to do in practice and may create unintended side-effects. The uncertainty may be the greatest in the transition from employee to self-employed when the risk of failure of the firm may also be highest. 


\section{Digital labour unions}

Organised labour, unions, originated from the desire to improve working conditions in industry and services. The same forces are now at work in the digital era. A number of organisations are developing to support and give guidance to freelancers in the sharing economy, including www.faircrowdwork.org in Germany and www.peers.org in the US. There are also various digital services that help freelancers improve their income, pay taxes, smooth income and ease cash flow, such as www.sherpashare.com and even.me. As freelancing is rising in importance, these organisations and the services they provide are trying to meet a demand for help and security not met elsewhere.

Through the app Even, for example, freelancers can even out their income over time for a fee, not unlike the idea behind risk-sharing provided by the public sector in many countries. For example, some labour unions in Sweden are already catering to the self-employed by providing advice, legal services and income insurance. These developments may be steps towards better risksharing in the economy between people in regular employment and freelancers. The legitimacy of the modern economies may hinge on large groups not being excluded - or less fully covered - by the established social safety nets.

\section{Concluding remarks}

Automation is in evidence everywhere, from advanced services to manufacturing. Digital technologies are disrupting several sectors at the same time. Though the changes underway are less transformative than the first phase of the Industrial Revolution, the changes are occurring within a compressed period of time. This makes it more difficult for workers to adapt by upgrading skills, learning new ones or switching jobs.

Fully automated vehicles will put pressures on millions of jobs in the transport sector. Many more would also be indirectly affected in global supply chains, including services that cater to drivers, notably hotels and restaurants.

The pressure on workers in the sector will likely depend on both the rate at which the technology is adapted as well as labour legislation. In countries with strict employment protection legislation (EPL), the main adjustment channel would likely be through a deterioration in wage prospects. Real wages might increase slower than in the service sector as a whole or they may even be reduced. Trade unions in Europe sometimes negotiate wage cuts as a way to avoid or reduce job losses. Since the pressures from technology are long-lasting, such a path would only bring temporary reprieve from conflict and the need for structural change.

In countries with less strict EPL, the job changes could occur quicker, leading to both job losses and to wage polarisation. The strength of this development will depend on rate at which the technology is adopted. It will also crucially depend on the labour market's ability to create new jobs. It is impossible to predict what those jobs might be, but three centuries of technological progress have not reduced employment levels in the world. Rather, the skill content of many jobs has increased, which has led to better productivity growth and better living standards.

The challenge this time around is that those losing jobs in the transport sector may find it hard to find new jobs without re-training and upgrading of skills, either to new jobs in the same sector or to other sectors of the economy, such as construction. The labour market has great capacity to cope with expanding or declining sectors, but the scale of the challenge could make the change more difficult and the social consequences severe.

A key policy to support the change is to promote life-long learning and adult education. Most jobs today will require an increasing amount of digital skills. Yet more than half of adult workers in the EU judge their digital skills too low to switch jobs according to a Eurostat survey. The survey did not include the US, but in all likelihood, the numbers are not too dissimilar. 
The risks are also increasing in the labour market but they are not evenly spread. In many OECD countries, the differences between insiders (those with permanent contracts) and outsiders (those on temporary work or the self-employed) are large and have increased over time. There is some urgency to considering policies to reduce the risks for those exposed to technical change and from globalisation. If not, political legitimacy and social cohesion could erode. With the rise of the gig economy, more people stand further from social security or from the benefits in collective wage bargaining agreements.

The amount of self-employment may increase. Such work has several advantages. The selfemployed have more flexibility on how much and when they work. For many immigrants, gig work and self-employment may also be a first step into the labour market that could lead to improved prospects or employment, as opposed to high risk of remaining unemployed.

But not all self-employment is voluntary and it contains a higher level of income risk. Policy makers could consider to improve the safety net for the self-employed and thus to somewhat narrow the gap compared to employment status. In this, there is no "one size fits all", as OECD member countries differ in social protection.

Could regulation aim to slow down the adoption of technical change over and above that motivated by safety concerns, thereby giving the labour market longer time to adapt? Such a policy would be harmful in the medium-to-long run. It would continue to hold back productivity growth, which is the key to increased prosperity. Wage and job polarisation would likely also continue unabated. Instead, structural change should be promoted, with focus on boosting the skills of the population and re-balancing the risks between insiders and outsiders. 


\section{References}

Acemoglu, D. (2003), "Labor- and Capital-Augmenting Technical Change." Journal of the European Economic Association. Vol. 1/1, pp.. 1-37.

Acemoglu, D. (2002), “Technical Change, Inequality, and the Labor Market.” Journal of Economic Literature. Vol. 40/1, pp. 7-72.

Acemoglu, D., S. Johnson and J. Robinson (2005), "Institutions as a Fundamental Cause of Long-Run Growth.” In P. Aghion and S.N. Durlauf, Handbook of Economic Growth. Volume 1A. Amsterdam: Elsevier.

Acemoglu, D. and D. Autor (2011), "Skills, Tasks and Technologies: Implications for Employment and Earnings." Handbook of Labor Economics. Vol. 4, pp. 1043-1171.

Acemoglu, D., D. Autor, D. Dorn, G.H. Hanson and B. Price (2014), "Return of the Solow Paradox? IT, Productivity, Employment in U.S. Manufacturing. NBER Working Paper No. 19837. National Bureau of Economic Research, Cambridge, MA.

Adermon, A. and M. Gustavsson (2015), "Teknisk utveckling och jobbpolarisering." SNS Analys No. 28. March 2015. Centre for Business and Policy Studies (SNS), Stockholm.

Agrawal, A., J. Horton, N. Lacetera, and E. Lyons (2015), "Digitalization and the Contract Labor market: A Research Agenda." In Avi Goldfarb, S.M. Greenstein and C.E. Tucker (eds.), Economic analysis of the digital economy. National Bureau of Economic Research Conference Report, May 2015. National Bureau of Economic Research, Cambridge, MA.

Akerman, A., I. Gaarder and M. Mogstad (2015). "The Skill Complementarity of Broadband Internet." NBER Working Paper No. 20826. National Bureau of Economic Research, Cambridge, MA.

Andrews, D., C. Criscuolo and P.N. Gal (2015). "Frontier Firms, Technology Diffusion and Public Policy: Micro Evidence from OECD Countries", OECD Productivity Working Papers, 2015-02, OECD Publishing, Paris. http://dx.doi.org/10.1787/5jrql2q2ji7b-en

Arntz, M., T. Gregory and U. Zierahn (2016), "The Risk of Automation for Jobs in OECD Countries: A Comparative Analysis". OECD Social, Employment and Migration Working Papers. No. 189. OECD Publishing. Paris. http://dx.doi.org/10.1787/5jlz9h56dvq7-en.

Autor, D. (2015), "Why are There Still so Many Jobs? The History and Future of Workplace Automation." Journal of Economic Perspectives. Summer 2015. Vol. 29/3. pp.3-30.

Autor, D.H., F. Levy and R.J. Murnane (2003), "The Skill Content of Recent Technological Change: An Empirical Exploration.” Quarterly Journal of Economics. Vol. 118/4, pp. 1279-1333.

Autor, D.H. and D. Dorn (2013), "The Growth of Low-Skill Service Jobs and the Polarization of the US labor market." American Economic Review. Vol. 10/5, pp. 1553-1597.

Beaudry, P., D.A. Green, and B.M. Sand (2016), “The Great Reversal in the Demand for Skill and Cognitive Tasks.” Journal of Labor Economics. Vol. 34:S1, pp. S199-S247.

Bessen, J. (2015), “Toil and Technology.”Finance \& Development. Vol. 52/1. IMF March 2015.

Blix, M. (2017 forthcoming). Digitalization, Immigration and the Welfare State. Edward Elgar. Cheltenham, UK and Northampton, MA, USA.

Bostrom, N. (2014), Superintelligence - Paths, Dangers and Strategies. Oxford University Press, Oxford.

Comin, D. and M. Mestieri Ferrer (2013), "If Technology Has Arrived Everywhere, Why has Income Diverged?” NBER Working Paper No. 19010. National Bureau of Economic Research, Cambridge, MA.

Cowen, T. (2015), Average is Over. Penguin Group, New York

Economist (2016), “After Moore's Law. Double, double, toil and trouble.” Technology Quarterly. 12 March. 
Economist (2015), “A Bridge to the Future.” The Economist. 15 September.

Edquist, H.O. and M. Henrekson (2006), "Technological Breakthroughs and Productivity Growth" Research in Economic History. Vol. 24, pp. 1-53.

Frey, C.B. and M.A. Osborne (2013). "Future Employment: How Susceptible Are Jobs to Computerisation?" Oxford Martin School Working Paper.

Eichhorst, W., P. Marx and C. Wehner (2016), "Labor Market Reforms in Europe: Towards More Flexicure Labor Markets?” IZA DP No. 9863. April.

Executive Office of the President (2016), Artificial Intelligence, Automation, and the Economy. December 2016. https://www.whitehouse.gov/sites/whitehouse.gov/files/documents/ArtificialIntelligence-Automation-Economy.PDF.

Goos, M., A. Manning and A. Salomons (2014), "Explaining Job Polarization: Routine-Biased Technological Change and Offshoring." American Economic Review. Vol. 104/8, pp. 2509-2526.

Hall, J. and A. Krueger (2015), "An Analysis of the Labor Market for Uber's Driver-partners in the United States." Working Paper No. 587. Princeton University, Industrial Relations Section.

Heyman, F., P-J. Norbäck and L. Persson (2016). 'Digitaliseringen och strukturomvandlingen i svenskt näringsliv." Expertgruppen för studier i offentlig ekonomi, Vol. 2016/4. Stockholm.

Heyman, F., P-J. Norbäck and L. Persson (2013), ”Var skapas jobben? En ESO-rapport om dynamiken i svenskt näringsliv 1990-2009." Expertgruppen för studier i offentlig ekonomi, Vol. 2013/3. Stockholm.

Heyman, F. (2016)., “Job Polarization, Job Tasks and the Role of Firms.” IFN Working Paper. No. 1123.

Johnson, S. (2014), How We Got to Now: Six Innovations That Made the Modern World. Penguin: New York.

Karabarbounis, L. and B. Neiman (2014), "The Global Decline of the Labor Share.” Quarterly Journal of Economics. Vol. 129/1, pp. 61-103.

Katz, L.F. and R.A. Margo (2013). "Technical Change and the Relative Demand for Skilled Labor: The United States in Historical Perspective." NBER Working Paper No. 18752. National Bureau of Economic Research, Cambridge, MA.

Knowles-Cutler, A., C.B. Frey and M.A. Osborne (2014), "Agiletown: The Relentless March of Technology and London's Response." Deloitte, London.

MacCrory, F., G. Westerman, Y. Alhammadi and E. Brynjolfsson (2015), "Racing with and Against the Machine: Changes in Occupational Skill and Composition in an Era of Rapid Technological Advance." Thirty Fifth International Conference on Information Systems, Auckland 2014.

MGI (2015), "A Labor Market that Works: Connecting Talent with Opportunity in the Digital Age." McKinsey Global Institute. June. http://www.mckinsey.com/global-themes/employment-andgrowth/connectingtalent-with-opportunity-in-the-digital-age (accessed 2 October 2016).

Mokyr, J. (2004), “Accounting For the Industrial Revolution.” in Floud, Roderick and Paul Johnson: The Cambridge economic history of Britain, Vol.1 Industrialisation, Cambridge University Press.

OECD (2016a), Society at a Glance 2016: OECD Social Indicators, OECD Publishing, Paris. http://dx.doi.org/10.1787/9789264261488-en.

OECD (2016b), OECD Compendium of Productivity Indicators 2016. OECD Publishing, Paris. http://dx.doi.org/10.1787/pdtvy-2016-en

OECD (2015a), In It Together: Why Less Inequality Benefits All. OECD Publishing, Paris. http://dx.doi.org/10.1787/9789264235120-en

OECD (2015b), Better Skills, Better Jobs, Better Lives - A Strategic Approach to Education and Skills Policies for the United Arab Emirates. Paris: OECD Publishing. 
OECD (2014a). OECD Employment Outlook 2014. OECD Publishing, Paris. http://dx.doi.org/10.1787/empl_outlook-2014-en

OECD (2014b), Measuring the Digital Economy: A New Perspective. OECD Publishing, Paris. http://dx.doi.org/10.1787/9789264221796-en

Pajarinen, M. and P. Rouvinen (2014), "Computeriziation Threatens One Third of Finnish Employment”. ETLA Brief No 22. http://pub.etla. /ETLA-Muis o-Brief-22.pdf.

Poeter, D. (2015), "How Moore's Law Changed History (and Your Smartphone).” PC Magazine. 19 April.

Ranft, F., M. Adler, P. Diamond, E. Guerrero and M. Laza (2016) Freeing the Road: Shaping the future for autonomous vehicles. A Policy Network Special Report. November. www.policynetwork.net.

Sundararajan, A. (2016), The Sharing Economy: The End of Employment and the Rise of CrowdBased Capitalism. The MIT Press, Cambridge, MA.

Vaughan-Whithead, D. Ed. (2016), Europe's Disappearing Middle Class? Evidence from the World of Work. Edward Elgar. Cheltenham, UK and Northampton, MA, USA.

Vigdor, J.L. and H.F. Ladd (2010), "Scaling the Digital Divide: Home Computer Technology and Student Achievement." NBER Working Paper No. 16078. National Bureau of Economic Research. Cambridge, MA.

Wolf, A. (2011), "Review of Vocational Education - The Wolf Report”, March 2011.

\section{Notes}

$1 \quad$ See IMF Article IV consultation with Japan from 2012.

2 Research has indicated, for example, that values tend to changes as societies become richer; for example, richer countries in the OECD region may ascribe greater value to safety than do developing countries. The whole claims process is done online. The customers report the claim on a web page, where they are even able to book contractors.

4 See, for example, http://www.scania.com/products-services/services/fleet management/.

$5 \quad$ http://www.volvotrucks.se/sv-se/services/fleet-management/driver-times.html.

$6 \quad$ Selected references for these points are given in each respective section below.

7 For an overview of advances in artificial intelligence and where we stand today see, for example, Bostrom (2014).

8 Wolf (2011) argues that we invest too much in education and that the quality in some areas is too low.

9 This point is also emphasised in the report Executive Office of the President (2016).

10 https://www.thetechpartnership.com

11 In Sweden, the trade unions and the employer organizations co-fund large "structural funds" which provide income insurance, retraining and advice for displaced manual and non-manual workers. They are open to all those with permanent contracts, but not to the self-employed or those on temporary contracts. 
